\title{
The Corticohippocampal Circuit, Synaptic Plasticity, and Memory
}

\author{
Jayeeta Basu ${ }^{1}$ and Steven A. Siegelbaum ${ }^{2,3,4}$ \\ ${ }^{1}$ Department of Neuroscience and Physiology, NYU Neuroscience Institute, New York University School \\ of Medicine, New York, New York 10016 \\ ${ }^{2}$ Kavli Institute for Brain Science, Columbia University, New York, New York 10032 \\ ${ }^{3}$ Department of Neuroscience, Columbia University, New York, New York 10032 \\ ${ }^{4}$ Department of Pharmacology, Columbia University, New York, New York 10032 \\ Correspondence: sas8@columbia.edu
}

Synaptic plasticity serves as a cellular substrate for information storage in the central nervous system. The entorhinal cortex (EC) and hippocampus are interconnected brain areas supporting basic cognitive functions important for the formation and retrieval of declarative memories. Here, we discuss how information flow in the EC-hippocampal loop is organized through circuit design. We highlight recently identified corticohippocampal and intrahippocampal connections and how these long-range and local microcircuits contribute to learning. This review also describes various forms of activity-dependent mechanisms that change the strength of corticohippocampal synaptic transmission. A key point to emerge from these studies is that patterned activity and interaction of coincident inputs gives rise to associational plasticity and long-term regulation of information flow. Finally, we offer insights about how learning-related synaptic plasticity within the corticohippocampal circuit during sensory experiences may enable adaptive behaviors for encoding spatial, episodic, social, and contextual memories.

Ever since the description by Scoville and EMilner (1957) of the profound anterograde amnesia in patient H.M. following bilateral temporal lobe resection, the hippocampus and surrounding temporal lobe structures have been extensively studied for their role in memory storage (Squire and Wixted 2011). Fifteen years after this initial finding, our understanding of the neurophysiological bases of hippocampal function were greatly enhanced by two breakthroughs: Bliss and Lomo's (1973) finding of activity-dependent long-term potentiation (LTP) of synaptic transmission in the hippo- campus, and the discovery of hippocampal place cells, neurons that encode the spatial position of an animal, by O'Keefe and Dostrovsky (1971). These discoveries stimulated a number of subsequent advances in our understanding of various forms of long-term synaptic plasticity at different stages of information processing in the corticohippocampal circuit, and how such plasticity contributes to memory storage and spatial representation.

Changes in synaptic efficacy ultimately act by altering the flow of information through neural circuits. Thus, a deeper understanding

Editors: Eric R. Kandel, Yadin Dudai, and Mark R. Mayford

Additional Perspectives on Learning and Memory available at www.cshperspectives.org

Copyright (C) 2015 Cold Spring Harbor Laboratory Press; all rights reserved; doi: 10.1101/cshperspect.a021733

Cite this article as Cold Spring Harb Perspect Biol 2015;7:a021733 
of how synaptic plasticity may subserve the encoding of memory requires a detailed knowledge of the paths of information flow through the corticohippocampal circuit, and how neural activity alters such information processing. Because there have been a number of recent excellent reviews on the importance of various forms of hippocampal synaptic plasticity in learning and memory (Morris et al. 2013; Bannerman et al. 2014), we largely focus on recent studies elucidating new features of the corticohippocampal circuit and new forms of plasticity that are tuned to the dynamics of this circuit.

\section{INFORMATION FLOW THROUGH THE CORTICOHIPPOCAMPAL CIRCUIT}

The hippocampus is important for both spatial and nonspatial forms of declarative or explicit memory (Squire et al. 2004), our knowledge of people, places, things, and events. In addition to encoding spatial information (Burgess and O'Keefe 1996), hippocampal neurons may also encode time during episodic events (Pastalkova et al. 2008; Kraus et al. 2013; Macdonald et al. 2013). How does the hippocampus encode and store these diverse memories? Although a definitive answer is lacking, our knowledge of the corticohippocampal circuit has greatly expanded in recent years, giving us a new appreciation for the multiple pathways by which information is processed in the hippocampus, an important step to achieving a circuit-level understanding of how this brain region stores memories.

Neurons wire up during development to form circuits that provide the architectural framework for information flow in the brain, enabling one brain area to influence another. Learning requires the association of information from different coactive brain areas during sensory experiences or the reprocessing of internal representations. Such associations result in plastic changes in synaptic and cell-wide functions that enable the formation of preferentially connected cell assemblies. At the level of a single neuron, this could occur through integration and association of inputs that coincide in time or space to influence the neuron's output.
As initially defined by Lorente de Nó (1934), the hippocampal region is composed of several subregions, including dentate gyrus (DG), and the CA3, CA2, and CA1 regions of the hippocampus proper. In the rat brain, there are estimated to be $\sim 1,000,000$ DG granule neurons, 300,000 CA3 pyramidal neurons, 30,000 CA2 pyramidal neurons, and 300,000 CA1 pyramidal neurons (Amaral and Witter 1989). In addition to these excitatory, principal neurons, there are many classes of inhibitory neurons in the hippocampus, although the total number of these inhibitory interneurons is only about $10 \%$ to $20 \%$ that of the principal cells. In CA1 alone, more than 20 types of GABAergic interneurons, have been classified according to their morphology, location, molecular and electrophysiological properties, and synaptic targets (Klausberger and Somogyi 2008). A key goal in hippocampal research is to gain an understanding as to how these different subregions process their inputs during learning to generate an output contributing to distinct aspects of memory encoding.

The Corticohippocampal Circuit. I: Classical Pathways

A typical CA1 pyramidal neuron in the rat receives a total of $\sim 30,000$ glutamatergic synaptic inputs distributed throughout its dendritic tree. In addition, it receives $\sim 1700$ GABAergic inputs (Megias et al. 2001). The major source of glutamatergic input to hippocampus comes from the entorhinal cortex (EC), a polymodal sensory association area that conveys both nonspatial sensory information (from the lateral entorhinal cortex [LEC]) and spatial information (from the medial entorhinal cortex $[\mathrm{MEC}])$. This sensory information is then processed within the hippocampus by several parallel circuits, ultimately leaving the hippocampus through CA1, the major output pathway (van Strien et al. 2009).

One striking feature of certain neurons in layers II and III of EC (EC LII and LIII), termed grid cells, is that they show spatially tuned firing patterns consisting of a hexagonally spaced array of grid-like firing fields that cover the extent 
of a two-dimensional environment (Fyhn et al. 2004; Hafting et al. 2005; Buzsaki and Moser 2013). Convergent input from a number of EC grid cells with slightly shifted firing fields has been proposed to produce an interference-like pattern that gives rise to the single well-defined place field of a hippocampal place cell (O'Keefe and Burgess 2005; Solstad et al. 2006; Bush et al. 2014).

Information from the superficial layers of EC reaches CA1 through both direct and indirect pathways (Fig. 1) (van Strien et al. 2009). The most well-characterized route is the indirect stream of information flow through the trisynaptic path. In this glutamatergic circuit, EC LII stellate cells send excitatory projections through the perforant path (PP) to granule cells of the DG, whose mossy fiber projections excite CA3 pyramidal neurons, which in turn excite CA1 pyramidal cells through the Schaffer collat- eral (SC) pathway (EC LII $\rightarrow$ DG $\rightarrow$ CA3 $\rightarrow$ CA1). In addition to the trisynaptic path, CA1 pyramidal neurons also receive a direct glutamatergic projection from EC LIII pyramidal neurons through the temporoammonic or PP $(\mathrm{PP}, \mathrm{EC}$ LIII $\rightarrow$ CA1).

These direct and indirect corticohippocampal inputs target distinct regions of the CA1 pyramidal neuron dendritic tree, with the SC inputs of the indirect pathway forming synapses on more "proximal" regions of CA1 pyramidal neuron apical dendrites in a layer of CA1 known as stratum radiatum (SR). In contrast, the direct PP inputs from EC form synapses on the "distal" regions of CA1 pyramidal neuron apical dendrites in a layer known as stratum lacunosum molecular (SLM). As a result of their distinct dendritic locations, these two inputs provide different levels of excitatory drive, due in part to differential attenuation by dendritic

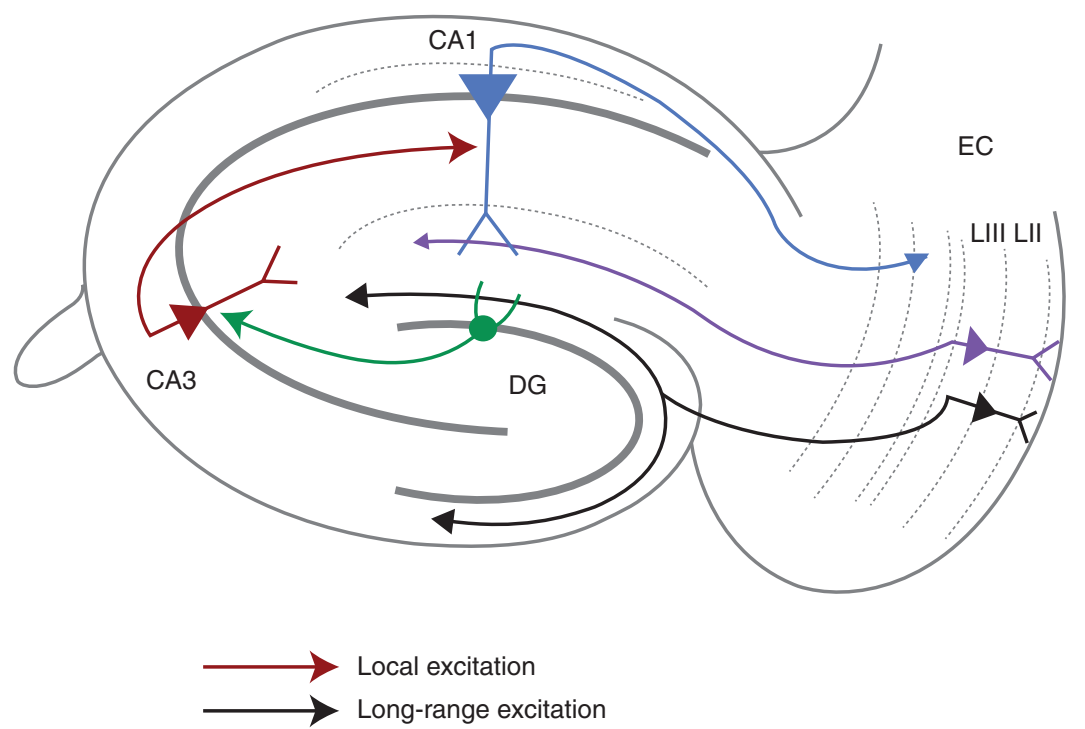

Figure 1. The classical corticohippocampal glutamatergic circuits. The classical corticohippocampal circuit comprises of glutamatergic input from the superficial entorhinal cortex (EC) layers (LII and LIII) to CA1 pyramidal neurons via the trisynaptic and monosynaptic paths; hippocampal back projections to the deep layers of EC complete the loop. Sensory signals drive the perforant path (PP, purple) inputs from EC LIII pyramidal neurons to distal CA1 pyramidal neuron dendrites (light blue). Activated EC LII pyramidal neurons send inputs to dentate gyrus (DG, black), which sends mossy fiber axons (dark green) to CA3 and then CA3 feeds onto CA1 neurons through Schaffer collateral (SC, dark red) excitatory inputs. A major output of the hippocampus arises from CA1 pyramidal neurons, which project to lateral ventricles (LVs) of EC. There is a 15-20 ms timing delay for transmission of information from EC LII to CA1 through the trisynaptic path compared with that from EC LIII to CA1 via the monosynaptic path. 
J. Basu and S.A. Siegelbaum

cable properties, with the PP synapses of the direct pathway providing weak excitation at the soma compared with the strong excitation provided by the SC inputs of the indirect pathway. These two classes of glutamatergic inputs also activate a number of different classes of GABAergic interneurons that inhibit CA1 output in a feedforward manner (Fig. 2).

The Corticohippocampal Circuit. II: Neoclassical Pathways

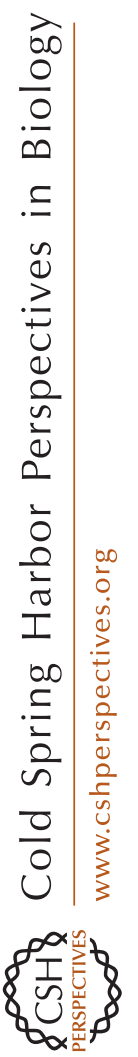

CA3 and CA1. However, recent studies using genetic approaches clearly show the unique molecular identity of CA2 pyramidal neurons (Lein et al. 2005; Hitti and Siegelbaum 2014; Kohara et al. 2014) and suggest the importance of the CA2 region in certain hippocampal functions (Piskorowski and Chevaleyre 2012).

Similar to CA1 neurons, CA2 pyramidal neurons receive both direct input from LII EC neurons (EC LII $\rightarrow$ CA2) onto their distal dendrites (Cui et al. 2013; Hitti and Siegelbaum 2014) and indirect input from the CA3 SC pathway $(\mathrm{EC} \quad \mathrm{LII} \rightarrow \mathrm{DG} \rightarrow \mathrm{CA} 3 \rightarrow \mathrm{CA} 2)$ onto their proximal dendrites (Chevaleyre and Siegelbaum 2010). In addition, CA2 also receives weaker mossy fiber excitatory input directly from DG granule cells (EC LII $\rightarrow$ DG $\rightarrow$ CA2) (Kohara et al. 2014).

In striking contrast to CA1, CA2 pyramidal neurons are excited much more strongly by their direct EC input compared with their SC input (Chevaleyre and Siegelbaum 2010). Fur-

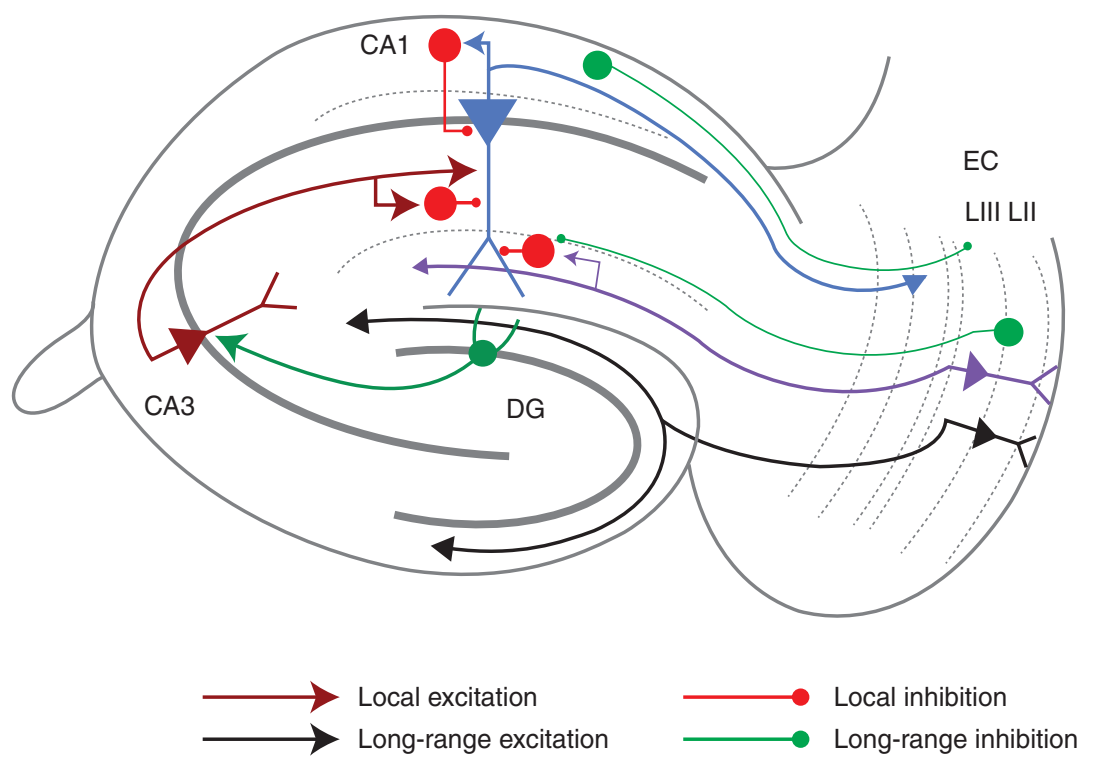

Figure 2. Local and long-range GABAergic connections. CA1 has several local GABAergic interneurons (red). These target the CA1 pyramidal neuron soma, axon, and dendrite to modulate pyramidal neuron activity in a domain-specific manner. Schaffer collateral (SC)- and entorhinal cortex (EC)-associated inhibitory microcircuits provide feedforward inhibition, whereas feedback inhibition is recruited recurrently when the CA1 pyramidal neuron fires an action potential. Long-range inhibitory projections (green) from the EC provide direct inhibition preferentially to local interneurons (INs) in CA1. Long-range projections from GABAergic neurons in stratum oriens (SO) of hippocampus to layer II/III (LII/LIII) of the EC have also been described. 
Integrating Synaptic Learning with Mnemonic Circuitry

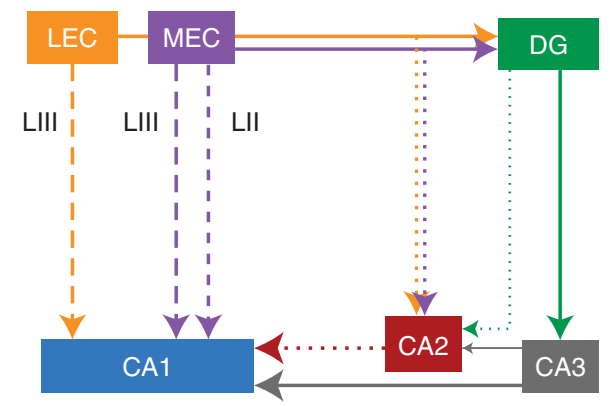

Figure 3. The updated corticohippocampal circuit. This circuit diagram integrates the recently discovered glutamatergic inputs from the entorhinal cortex (EC) to the hippocampus as well as connections within the hippocampus. In addition to the classical trisynaptic (EC layer II [LII] $\rightarrow$ dentate gyrus $[\mathrm{DG}] \rightarrow \mathrm{CA} 3 \rightarrow \mathrm{CA} 1$, solid line) and monosynaptic (EC layer III (LIII) $\rightarrow$ CA1, large-dashed lines) pathways of information flow, CA1 also receives monosynaptic projections from LII of the medial entorhinal cortex (MEC) (small dashed line) and CA2 receives direct inputs from LII of both MEC and lateral entorhinal cortex (LEC) (dotted lines). Within the hippocampus, CA2 sends prominent inputs to CA1, targeting dendritic domains (stratum oriens $[\mathrm{SO}] /$ stratum radiatum $[\mathrm{SR}]$ ) (red) that overlap with the $\mathrm{CA} 3 \rightarrow \mathrm{CA} 1$ inputs. $\mathrm{CA} 2$ also receives weak inputs from DG and CA3. The thickness of the arrowed lines emphasizes the strength of the input connection.

thermore, a CA2 pyramidal neuron forms a strong multiquantal synaptic connection with a CA1 pyramidal neuron, eliciting an excitatory postsynaptic potential (EPSP) that is significantly larger than the uniquantal response at the synaptic connection between a CA3 and CA1 pyramidal neuron (Chevaleyre and Siegelbaum 2010). As a result, CA2 mediates a powerful disynaptic circuit directly linking cortical input to hippocampal output $(\mathrm{EC} \rightarrow \mathrm{CA} 2 \rightarrow$ CA1), which operates in parallel to the trisynaptic path. Although CA2, in principle, can participate in a quadrisynaptic path linking EC to $\mathrm{CA} 1(\mathrm{EC} \rightarrow \mathrm{DG} \rightarrow \mathrm{CA} 3 \rightarrow \mathrm{CA} 2 \rightarrow \mathrm{CA} 1)$, strong feedforward inhibition from $\mathrm{CA} 3$ to CA2 normally limits efficient information flow through this pathway.

More recent evidence suggests the existence of an additional direct pathway from EC to CA1
(Fig. 3) involving projections from LII pyramidal neurons of MEC (EC LII $\rightarrow$ CA1) (Kitamura et al. 2014). These inputs also target the CA1 pyramidal neuron distal dendrites but are weaker compared with the EC LIII inputs. In addition, the EC LII projections provide strong excitatory drive to local CA1 interneurons, thus recruiting pronounced feedforward inhibition onto CA1 pyramidal neurons. In addition to the LII and LIII excitatory inputs to CA1, MEC also sends direct GABAergic inputs to all fields of the hippocampus (Fig. 2) (Melzer et al. 2012). These inhibitory projections likely originate in LII/III of the EC and show a bias toward innervating hippocampal GABAergic interneurons near the SR/SLM border in CA1.

\section{Potential Function of Parallel Corticohippocampal Streams}

What is the purpose of the parallel streams of corticohippocampal information flow? Do the various hippocampal subfields (DG, CA1, CA2, and CA3) act as semi-independent parallel information-processing units? Does the information received by these neighboring subfields differ in its cellular origin or in its quality? Or do the hippocampal subfields act primarily as serial processing stations that are transforming cortical input in discrete and successive steps?

The fact that CA1 integrates a direct representation of spatial and nonspatial sensory information (originating in the MEC and LEC) with information that has been processed through hippocampal disynaptic and trisynaptic circuits has led to the idea that CA1 performs a comparison between the immediate spatiosensory context and stored mnemonic information. However, the nature of the comparison is not known.

One suggestion is that CA1 acts as a novelty detector, comparing stored memory-related information in DG and CA3 with ongoing direct sensory representations from the EC (Lisman and Grace 2005; Duncan et al. 2012). The strong feedforward inhibition triggered by the direct EC inputs may serve as an inhibitory gate on information flow arriving from the SC inputs 
by means of the action of dopaminergic novelty signals (Lisman and Grace 2005). Another suggestion is that the direct inputs may provide instructive signals for assessing the salience of information flow through the trisynaptic path using a timing-dependent plasticity rule, which is tuned to the delay-line architecture of the hippocampal circuit (Dudman et al. 2007). Because of the two extra synapses and conduction and integration delays, information flowing through the trisynaptic path arrives at CA1 neurons some 15 to $20 \mathrm{msec}$ after the arrival of information through the direct EC inputs (Yeckel and Berger 1990). Such a circuit design allows for integration and comparison of temporally coordinated inputs that may contribute to the encoding of sequential episodic events (Dudman et al. 2007; Ahmed and Mehta 2009; Mizuseki et al. 2009; Basu et al. 2013).

\section{The Corticohippocampal Circuit.} III: Outputs of the Hippocampus

CA1 pyramidal neurons provide the major output from the hippocampus, sending projections to a number of brain regions, including the neighboring subiculum, perirhinal cortex, prefrontal cortex, and amygdala (van Groen and Wyss 1990). A small fraction of pyramidal neurons from dorsomedial CA1 also project to the restrosplenial cortex (Wyss and Van Groen 1992). One particularly strong output goes back to the EC, in which CA1 axons excite layer V pyramidal cells, which in turn send excitatory feedback input to the EC LII/III, thereby completing an $\mathrm{EC} \rightarrow$ hippocampus $\rightarrow \mathrm{EC}$ loop (Figs. 1 and 3) (Naber et al. 2001). In addition to excitatory pyramidal neuronal outputs, certain GABAergic neurons in specific layers of CA1 project directly to retrohippocampal and cortical areas. These include longrange GABAergic projections from somatostatin (SOM) and mGluR1a expressing inhibitory neurons in stratum oriens (SO) to the subiculum and medial septum (MS) (Jinno et al. 2007; Fuentealba et al. 2008). GABAergic cells located in the border of SR and SLM (often expressing muscarinic AChRs or mGluR1as) project to retrosplenial cortex and indusium gresium
(Jinno et al. 2007). There are also SOM-expressing GABAergic neurons in $\mathrm{SO}$ of $\mathrm{CA} 1$ and hilus of DG that send direct projections to the superficial layers of MEC (Fig. 2) and striatum (Melzer et al. 2012). The long-range inhibitory projections are often highly myelinated (Jinno et al. 2007) and predominantly target local GABAergic interneurons at the projection sites (Melzer et al. 2012). These properties have led to the suggestion that long-range inhibitory projections may be important for coordinating the timing between the hippocampus and its cortical targets (Buzsaki and Chrobak 1995) and could serve a disinhibitory role (Caputi et al. 2013).

At present, there are conflicting data as to whether CA2 neurons project outside of the hippocampus. One study using a cell-type-specific rabies virus retrograde tracing strategy reported that $\mathrm{CA} 2$ pyramidal neurons send projections to EC LII neurons (Rowland et al. 2013), the source of the direct cortical input to CA2 (Hitti and Siegelbaum 2014; Kohara et al. 2014). CA2 has also been reported to project to the supramammillary nucleus (Cui et al. 2013), a hypothalamic region long known to provide strong input to CA2 (Haglund et al. 1984; Vertes 1992; Magloczky et al. 1994; Ochiishi et al. 1999; Kiss et al. 2000).

\section{The Corticohippocampal Circuit. IV: Heterogeneity within the CA1 Pyramidal Neuron Population}

Although many studies treat CA1 pyramidal neurons as a uniform population, there is increasing evidence for heterogeneity along each of the three spatial axes of the hippocampus: the septotemporal (or dorsoventral) longitudinal axis, the proximodistal transverse axis (CA2 to subiculum), and the deep superficial radial axis in the stratum pyramidale (SP) cell body layer (with deep referring to pyramidal neurons closer to SO and superficial referring to pyramidal neurons closer to SR).

Along the transverse axis, proximal CAl neurons (closer to the $\mathrm{CA} 2$ border) receive direct input primarily from the MEC, whereas distal CA1 neurons (closer to the border with 
subiculum) receive direct input primarily from the LEC (Fig. 3) (Ishizuka et al. 1990; Witter and Amaral 1991). This topographical arrangement is reversed in subiculum. Pyramidal neurons in CA1 and subiculum also show a strong proximodistal gradient from regular firing in CA1 to prominent burst firing in subiculum (and CA3) (Jarsky et al. 2008; Kim and Spruston 2012).

Marked differences in pyramidal neuronfiring properties along the transverse axis have also been recorded in vivo. Thus, distal CA1 pyramidal neurons, which receive largely nonspatial input from the LEC, show dispersed firing during spatial navigation and tend to have multiple place fields (Henriksen et al. 2010) and display increased $20-40 \mathrm{~Hz}$ coupling with the LEC during spatial associational learning behavior (Igarashi et al. 2014). As expected, the firing of proximal CA1 pyramidal neurons are more strongly coupled to MEC neuron firing at theta frequencies and show greater spatial modulation and more compact place fields compared with their distal counterparts (Henriksen et al. 2010).

Since the initial studies of Lorente de Nó (1934), it has been suggested that there may be two separate sublayers of CA1 pyramidal neurons along the radial axis: a relatively tight superficial layer (closer to SR) and a broader more dispersed deep layer (closer to SO) (Slomianka et al. 2011). Molecular evidence supporting this view comes from the finding that the superficial neurons, but not deep pyramidal neurons, are enriched in calbindin and zinc (Baimbridge and Miller 1982; Baimbridge et al. 1982; Dong et al. 2008; Slomianka et al. 2011). During development, expression of Sox 5 specifies pyramidal neurons in the deep layers, whereas the coexpression of Satb2 and Zbtb20 may determine the fate of superficial neurons (Nielsen et al. 2010; Xie et al. 2010). Morphologically, the deep neurons have fewer oblique dendrites in SR and more extensive branching in SO than do superficial neurons (Bannister and Larkman 1995b). The two sublayers also have distinct input-output connectivity, with deep neurons receiving preferential input from CA2 pyramidal neurons (Kohara et al. 2014) and local inhibitory parvalbumin-positive basket cells (Lee et al. 2014), the latter distinction first reported by Lorente de Nó (1934).

Importantly, the two layers show different functional properties in vitro and during behavior. The presence in superficial neurons of calbindin, which buffers calcium and interferes with $N$-methyl-D-aspartate receptor (NMDAR)-dependent LTP, may lead to plasticity differences in the two populations (Arai et al. 1994; Bannister and Larkman 1995a,b). The superficial cells show a larger influence of the hyperpolarization-activated cation current, Ih, which contributes to the resting integrative properties of the neurons (Jarsky et al. 2008). In vivo, the deep neurons show a greater tendency for spatial tuning during navigation as well as stronger modulation during slow wave sleep (Mizuseki et al. 2011).

Finally, there are functional and structural differences along the longitudinal axis of the hippocampus, including differences in protein expression along the dorsoventral axis that actually define three distinct regions: dorsal, intermediate, and ventral hippocampus (Dong et al. 2010). In addition, ventral hippocampal CA1 pyramidal neurons are more excitable than dorsal neurons, perhaps resulting from a stronger expression of the HCN1 cation channel in the ventral hippocampus (Dougherty et al. 2013).

Dorsal hippocampal place cells show more precise place fields compared with ventral hippocampal place cells, whose place fields are more diffuse (Jung et al. 1994), although this may not degrade the ability of the ventral hippocampus to encode spatial position because of the higher ventral cell-firing rates (Keinath et al. 2014). This difference in place-field size corresponds to a dorsoventral gradient of increasing grid field size and spacing in MEC LII grid cells (Brun et al. 2008), which show a topographic dorsoventral projection to the hippocampus (van Strien et al. 2009). Dorsal and ventral hippocampi also differ in their outputs. Ventral hippocampus projects more strongly to prefrontal cortex and amygdala compared with dorsal hippocampus (Ishikawa and Nakamura 2006). Moreover, these differences reflect the distinct behavioral roles of these two regions, with dorsal hippocampus more important for 
J. Basu and S.A. Siegelbaum

spatial and contextual memory and ventral hippocampus more important for emotional- and anxiety-related behaviors (Fanselow and Dong 2010).

\section{ROLE OF DISTINCT REGIONS OF THE CORTICOHIPPOCAMPAL CIRCUIT IN LEARNING AND MEMORY}

Studies using both conventional lesions and sophisticated genetic approaches have identified specific roles of distinct corticohippocampal circuit elements in learning and memory (Fig. 4), and have begun to identify the role of specific regions in disease. CA1, which provides the major output of the hippocampus, is essential for most, if not all, forms of hippocampaldependent memory as CA1 lesions in both humans and other mammalian species, including rodents, leads to severe memory impairment (Zola-Morgan et al. 1986; Squire 2004). At present, the role of the hippocampus and CA1 in memory recall is somewhat unclear, as certain patients with hippocampal damage (including H.M.), as well as lesioned animals, are able to recall remote memories formed before hippocampal damage (Squire 2004). However, other patients with hippocampal CA1 lesions have both severe retrograde and anterograde loss of episodic memory (Bartsch et al. 2011).

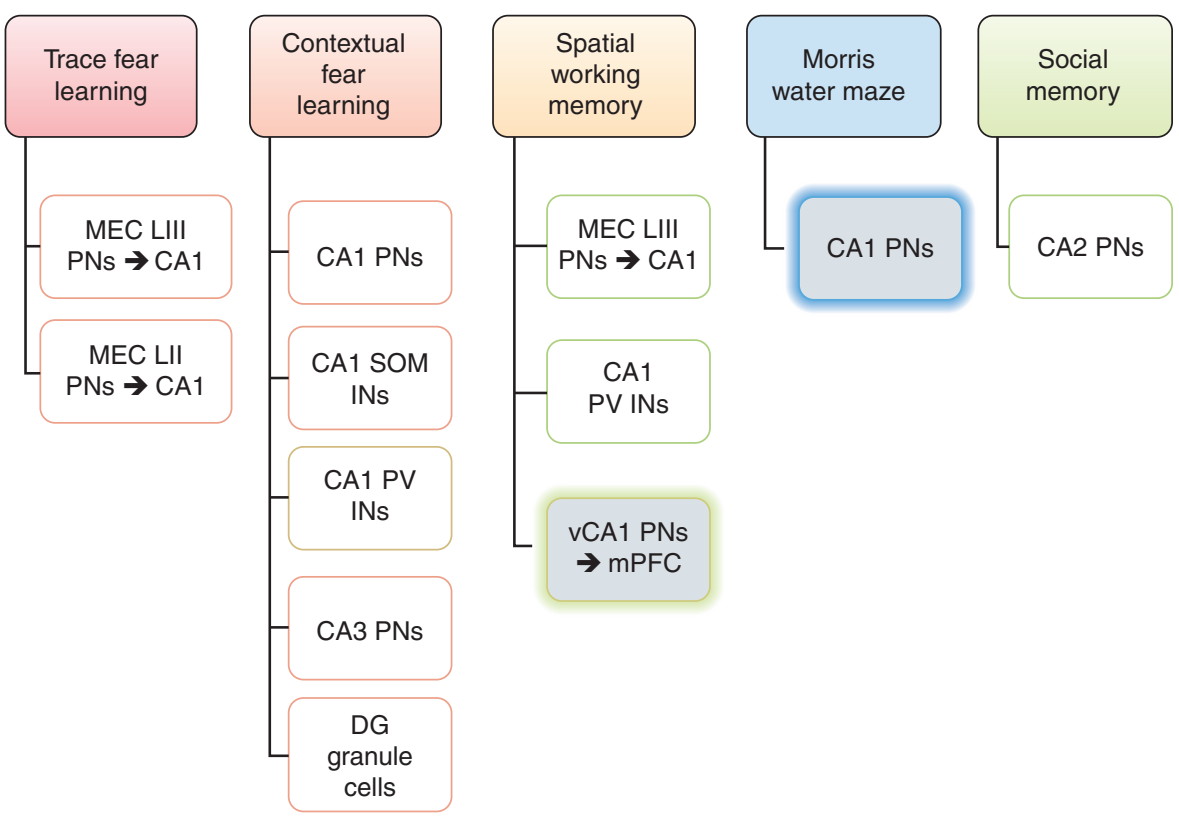

Figure 4. Cellular and circuit correlates of behavioral learning. Genetic and classical lesions have elucidated how the different pathways and cell populations comprising the corticohippocampal circuit support various forms of associational learning and declarative memory functions. All subfields, except the grayed boxes, show results from behavioral experiments involving genetically targeted cell type or input specific functional manipulations. Gray boxes indicate physical or chemical lesion-based findings. Both the medial entorhinal cortex (MEC) layer II (LII) (Kitamura et al. 2014) and layer III (LIII) (Suh et al. 2011) glutamatergic inputs to CA1 are used for trace fear conditioning (TFC). CA1 pyramidal neurons (PNs) (Goshen et al. 2011), CA3 pyramidal neurons (Nakashiba et al. 2008), dentate gyrus (DG), granule cells (Nakashiba et al. 2012; Kheirbek et al. 2013), parvalbumin (PV) interneurons (INs) (Donato et al. 2013), and somatostatin (SOM) interneurons (Lovett-Barron et al. 2014) have all been found to be involved in contextual fear-learning behavior. Spatial working memory requires activity in the MEC LIII pyramidal neurons projections to CA1 (Suh et al. 2011; Yamamoto et al. 2014), CA1 PV interneurons (Murray et al. 2011), and the ventral hippocampal projections to the prefrontal cortex (Wang and Cai 2006). 
Moreover, a number of studies have shown the activation of the hippocampus, including CA1, during memory recall (Rugg and Vilberg 2013). Furthermore, optogenetic experiments have shown that temporally precise and transient inactivation of dorsal CA1 pyramidal neurons in rodents markedly impairs recall (Goshen et al. 2011). This suggests that long-term inactivation of the hippocampus through genetic or physical lesions may result in a variable degree of compensatory changes in other brain regions that enable recall in some individuals but not in others.

One surprising finding is that lesions of dorsal CA1 lead to a disruption of grid cell spatial tuning patterns within the EC, which provides the major input to the hippocampus (Bonnevie et al. 2013). In addition, hippocampal place-cell activity can precede the appearance of well-defined EC grid-cell firing during early postnatal development (Langston et al. 2010; Wills et al. 2010). These results suggest that feedback from the hippocampus may be necessary for optimal grid-field formation. As "border cells" that fire when an animal reaches the edges of an environment develop in the EC before grid cells, it has been proposed that these border cells may provide the input that gives rise to hippocampal place cells (Bjerknes et al. 2014). Furthermore, removal of CA1 inputs to the EC converts grid cells into head direction cells (Bonnevie et al. 2013).

In contrast to the profound changes produced by lesions in CA1, lesions of DG appear to cause more subtle changes in memory performance. Although such lesions do not disrupt a basic form of contextual fear conditioning, they do result in an impaired ability to distinguish between closely related environments, a process termed pattern separation (Leutgeb et al. 2007; Sahay et al. 2011; Nakashiba et al. 2012), the ability to distinguish between closely related environments. Interestingly, DG is a prominent site of adult neurogenesis (Drew et al. 2013) and the newborn neurons appear preferentially involved in pattern separation (Nakashiba et al. 2012). DG is also affected preferentially during age-related memory loss (Small et al. 2011; Pavlopoulos et al. 2013), whereas Alzheimer's disease initially targets the EC (Braak and Braak 1985). Interestingly, a recent study (Kheirbek et al. 2013) using optogenetic activation and silencing of granule cells shows that dorsal DG is important for encoding but not retrieval of contextual fear memories. Genetic knockout studies suggest that CA3 is important for pattern completion (Nakazawa et al. 2002), the ability to recall a memory from partial cues, and one-trial forms of contextual learning (Fig. 4), in which a strong aversive stimulus results in rapid memory formation without the usual need for repeated trials and spatial reference memory.

The primary role of the trisynaptic path in memory formation and spatial encoding was called into question by physical (Brun et al. 2002) and genetic (Nakashiba et al. 2008) lesion studies, which showed that removal of CA3 input to CA1 had surprisingly little effect on spatial reference memory performance in the Morris water maze (MWM), or on the rate of CA1 neuron place-cell firing in vivo. To explain these findings, it was postulated that the direct EC LIII (and possibly EC LII) inputs to CA1 might be sufficient to drive normal CA1 firing rates to support hippocampusdependent memory.

In support of the importance of the direct EC LIII inputs in spatial memory, chemical and electrolytic lesions of the MEC inputs to CA1 were found to lead to a degradation of place-field precision (Brun et al. 2008) and deficits in consolidation of spatial long-term memory (Remondes and Schuman 2004). However, highly selective genetic lesions or optogenetic silencing of glutamatergic MEC LIII inputs to CA1 impaired trace fear conditioning (TFC), a form of temporal association memory, and spatial working memory, but did not perturb spatial reference memory, contextual fear conditioning, or place-cell firing (Fig. 4) (Suh et al. 2011; Kitamura et al. 2014; Yamamoto et al. 2014). The recently identified EC LII pyramidal neuron projections to CA1 are also involved in trace fear learning but have an opposite role to EC LIII inputs, acting to inhibit fear memory by recruiting a population of dendritic targeting CA1 inhibitory neurons (Kitamura et al. 2014). 
The suggestion that the direct EC inputs to CA1 can compensate for loss of CA3 inputs is difficult to reconcile with the finding that the direct EC inputs to CA1 provide only a weak excitatory drive and so cannot elicit CA1 output, except when stimulated in high-frequency bursts (Jarsky et al. 2005). One alternative explanation is that the residual function of CA1 pyramidal neurons and memory task performance following CA3 lesions is maintained by activity through the disynaptic pathway mediated by CA2. However, when output from CA2 pyramidal neurons was silenced using a Cre-dependent viral vector to express tetanus toxin in the Amigo2-Cre mouse line, there was little change in spatial reference memory (MWM), object or odor recognition (including social odors), or context memory (contextual fear conditioning). Surprisingly, inactivation of CA2 did cause a profound deficit in social memory, the ability of an animal to recognize and remember individual members of its species (Fig. 4) (Hitti and Siegelbaum 2014). The role of the hippocampus in social memory in humans is well illustrated by the case of H.M., who could no longer form memories of new individuals following temporal lobe resection (Corkin 2002).

The finding that spatial and contextual fear conditioning are intact following lesioning of all three major classes of inputs to CA1 is somewhat surprising, and could indicate that one or two input pathways may be able to maintain memory storage capacity in the absence of the third pathway. Perhaps this explains why there are the parallel processing routes for information flow from the EC to hippocampus that are sufficient but not necessary to sustain the critical functions of the hippocampus, namely, spatial and contextual encoding. Another possibility is that long-term lesions and cell-typespecific genetic ablations may lead to compensatory mechanisms that result in strengthening or redistribution of functional gain of otherwise weaker pathways, thus enabling them to sustain the function of the lesioned circuit. Studies using temporally precise inactivation of pairs of hippocampal regions and inputs may help determine whether different regions do indeed provide such compensation.

\section{EXTRAHIPPOCAMPAL AND NEUROMODULATORY TUNING OF CORTICOHIPPOCAMPAL CIRCUITS DURING LEARNING AND MEMORY}

There are several neuromodulatory inputs to the various subfields of the hippocampus that strongly influence synaptic transmission and activity in the corticohippocampal circuit and contribute significantly to learning behaviors. These projections often target specific subpopulations of GABAergic interneurons in addition to their glutamatergic counterparts. Furthermore, there are substantial differences in the innervation patterns and behaviorally triggered activity of such inputs.

Aminergic modulatory inputs from midbrain and brain stem can markedly alter the function of various circuit elements and modulate memory formation. The importance of dopamine (DA) in regulating short-term synaptic transmission, long-term plasticity, and learning and memory has received a great deal of attention (Jay 2003; Lisman and Grace 2005). Studies using bath application of dopaminergic agonists generally report a strong suppression of the direct EC input to CA1, with little effect on the SC input (Lisman and Grace 2005; Ito and Schuman 2007).

Other studies show that DA facilitates the induction of a late phase of LTP at the SC $\rightarrow$ CA1 pyramidal neuron synapses by activation of D1/D5 receptors and an increase in cAMP levels both in vitro (Huang and Kandel 1995) and in vivo (Lemon and Manahan-Vaughan 2006). Moreover, DA has been found to be important for both hippocampal memory formation (Wilkerson and Levin 1999; Rossato et al. 2009; Bethus et al. 2010) and the stability of place-field representations (Kentros et al. 1998). Such results have led to the suggestion that DA release in response to novelty acts as a reward signal to enhance memory storage by increasing the relative influence of the hippocampal SC inputs to CA1 versus the EC inputs (Lisman and Grace 2005).

Cholinergic inputs also play a key role in regulating hippocampal function and memory. A recent study (Lovett-Barron et al. 2014) found 
that cholinergic input from the MS activates a class of SOM-positive dendritic targeting interneurons during the unconditioned aversive stimulus in a contextual fear-conditioning task. Interfering with this circuit-based mechanism by silencing dendrite-targeting inhibition in CA1 during presentation of the unconditioned stimulus impaired fear learning (Fig. 4). The increased inhibition at CA1 pyramidal neuron distal dendrites acts to suppress any coincident excitatory inputs conveyed by the EC direct pathway. The investigators postulate that such a mechanism may be useful for preventing cortical sensory information representing the aversive stimuli from becoming confounded with the representation of the context, enabling recall of the context alone to trigger a fear response.

Another extrahippocampal modulatory input to CAl comes from the thalamic nucleus reuniens (NuRe), which receives input from the prefrontal cortex. Anatomical and electrophysiological studies show that the NuRe sends excitatory inputs to the SLM region of CA1, where it innervates both local interneurons and the distal dendrites of pyramidal neurons (Wouterlood et al. 1990; Hirayasu and Wada 1992; Dolleman-Van der Weel et al. 1997, 2009). Xu and Südhof (2013) recently found that this pathway is important for specificity of contextual representations by preventing the generalization of fear memory, based on experiments in which the NuRe projections were selectively silenced.

The hippocampal CA2 region also receives neuromodulatory inputs from various midbrain nuclei in addition to its EC LII and intrahippocampal inputs. These include the reciprocal projections between $\mathrm{CA} 2$ and the supramammillary nucleus (SUM), MS, diagonal band of Broca (DBB) as well as afferent vasopressinergic projections from paraventricular nuclei of the hypothalamus to CA2 (Cui et al. 2013; Hitti and Siegelbaum 2014). In fact, the strong input from the hypothalamic nuclei as well as a high level of expression of the arginine vasopressin receptor AVPR1b likely contributes to the ability of the CA2 region to participate in a specific circuit for the storage and recall of social memory (Young et al. 2006; Hitti and Siegelbaum 2014). A global knockout of
AVPR1b (Wersinger et al. 2002) shows decreased social memory, the ability to remember interactions with conspecifics, and decreased temporal memory for event order (DeVito et al. 2009). Whereas AVPR1b is widely expressed (albeit at lower levels) throughout the brain, including in hypothalamus, the deficit in socially motivated aggressive behavior in the knockout mouse was partially rescued by selective expression of AVPR1b in dorsal CA2 using spatially, but not genetically, targeted viral injections (Pagani et al. 2014). It will be of interest to determine whether AVPR1b expression in CA2 is also required for formation of social memory (Hitti and Siegelbaum 2014).

\section{LONG-TERM SYNAPTIC PLASTICITY IN THE CORTICOHIPPOCAMPAL CIRCUIT IN LEARNING AND MEMORY}

One of the striking features of synapses in the central nervous system, especially those in the corticohippocampal circuit, is the extent to which their strength can be regulated for prolonged periods of time by different patterns of synaptic activity, a process termed activity-dependent synaptic plasticity. In some instances, the plasticity is homosynaptic in that activity within a given synaptic pathway leads to altered strength of synaptic communication at the same synapses that were activated (Fig. 5A,B). Other examples of synaptic plasticity are heterosynaptic in that activity in one synaptic pathway influences the function of another pathway (Fig. 5C). Although there is a great deal of correlative evidence linking forms of plasticity to hippocampal-dependent memory formation, the precise role of plasticity mechanisms in learning and memory formation remains controversial (see reviews Morris 2013; Bannerman et al. 2014). This complexity likely reflects the fact that there are multiple forms of plasticity that differ in the pattern of activity required for their induction, the molecular mechanisms for both their induction and expression, and the duration of the plastic changes (Fig. 5).

\section{Homosynaptic Plasticity}

The importance of homosynaptic forms of activity-dependent plasticity was first postulated 
J. Basu and S.A. Siegelbaum

A1
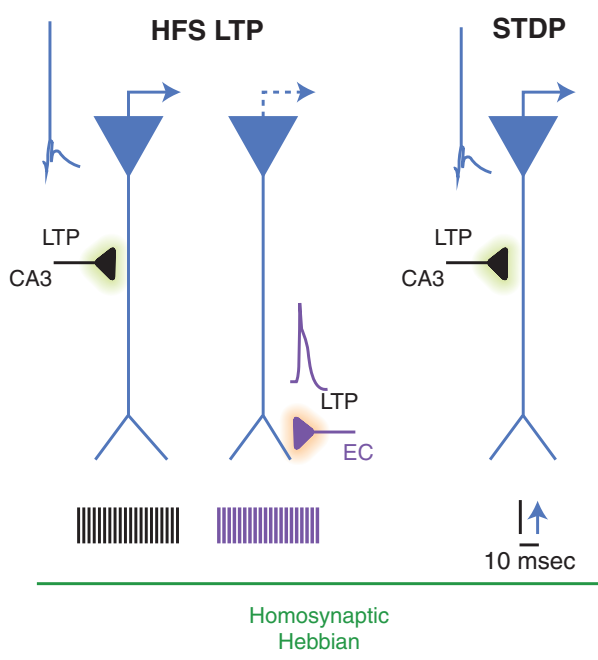

A2

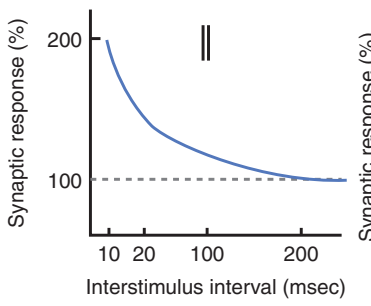

B1

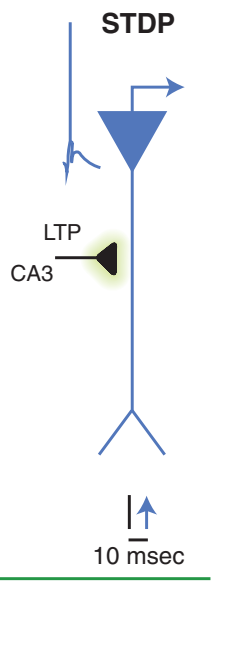

C1

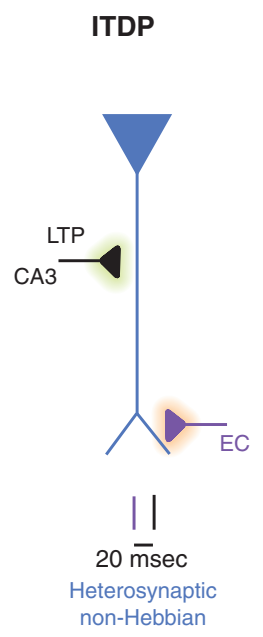

B2

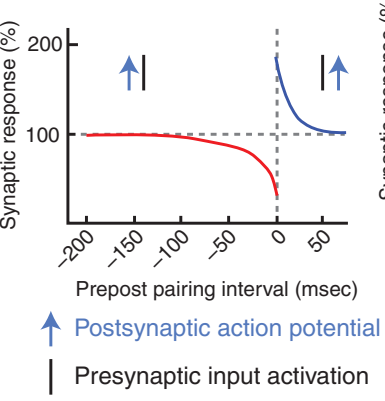

C2

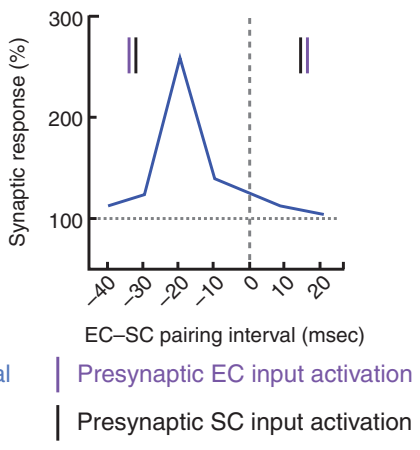

Figure 5. Synaptic learning motifs and their temporal fidelity. Scheme showing how different synaptic learning rules emerge in the CA1 microcircuit from temporally patterned activity of synaptic inputs (CA3 to CA1 Schaffer collateral [SC] inputs in black; entorhinal cortex [EC] to CA1 inputs in purple) and the postsynaptic CA1 pyramidal neuron (blue). (A1) High-frequency stimulation long-term potentiation (HFS LTP) is a homosynaptic form of synaptic learning in which strong tetanic stimulation (200 pulses at $20-100 \mathrm{~Hz}$ ) of the CA3 or EC inputs can strengthen the synaptic output of that specific active input pathway. HFS LTP is Hebbian in that its induction requires Schaffer collateral (SC) input stimulation to evoke somatic spikes, or perforant path (PP) input stimulation to trigger dendritic spikes in the postsynaptic CA1 pyramidal neurons. (A2) Plot depicting the frequency dependence of SC HFS LTP. Postsynaptic excitatory response recorded in CA1 pyramidal neurons plotted as a function of the interstimulus interval for tetanic stimulation of the CA3-CA1 SC inputs. Preinduction baseline synaptic response is 100\%. (Adapted, with values, from Thomas et al. 1996; Aihara et al. 1997; Zakharenko et al. 2003; Alarcon et al. 2004.) (B1) Spike-timing-dependent plasticity (STDP) is induced in CA1 pyramidal neurons by temporally precise pairing of synaptic inputs from CA3 with a postsynaptic spike triggered by injecting a brief current step in the soma. The pairing is typically repeated 50-100 times at $10 \mathrm{~Hz}$. (B2) LTP is induced when the presynaptic input precedes the postsynaptic spike by $5-20 \mathrm{msec}$, whereas long-term depression (LTD) prevails when the pairing sequence is reversed (postsynaptic spike before the presynaptic input). (-) Timing intervals indicate pre- before postsynaptic pairing. (Adapted from data in Bi and Poo 1998; Debanne et al. 1998; Nishiyama et al. 2000.) (C1) Input-timing-dependent plasticity (ITDP) is induced when EC and SC inputs are stimulated $20 \mathrm{msec}$ apart (EC before SC) at subthreshold strengths (hence, non-Hebbian) for $90 \mathrm{sec}$ at a $1 \mathrm{~Hz}$ frequency. ITDP is expressed in the CA1 pyramidal neuron as a long-term potentiation (LTP) of the SC- mediated postsynaptic depolarization without a change in the PP-evoked response (hence, heterosynaptic). (C2) Induction of ITDP is finely tuned to the $20 \mathrm{msec}$ pairing interval, even a $10 \mathrm{msec}$ deviation from this preferred timing interval is ineffective. ( - ) Timing intervals indicate EC before SC input pairing. (Adapted from data in Basu et al. 2013.) 
by Donald Hebb (1949) on theoretical grounds as a mechanism for forming neural assemblies. According to Hebb:

When an axon of cell A is near enough to excite a cell B and repeatedly or persistently takes part in firing it, some growth process or metabolic change takes place in one or both cells such that A's efficiency, as one of the cells firing $B$, is increased.

Hebb's idea was that this type of synaptic learning rule would provide for the wiring of neuronal assemblies with common response properties. For example, it could explain how a linear array of neighboring retinal ganglion cells and their lateral geniculate targets, which both have circular receptive fields, are able to connect to a common cortical neuron in primary visual cortex to generate typical response selectivity to oriented bars of light. However, Hebbian plasticity is also ideally suited for the formation of neural ensembles that encode a given memory.

\section{Hebbian LTP}

LTP of synaptic transmission represents the classic example of a Hebbian synaptic learning rule. Bliss and Lomo induced LTP by a brief, strong tetanic stimulation of the PP inputs to DG in anesthetized rabbits, which produced a longlasting enhancement in the strength of excitatory synaptic transmission from PP to DG that lasted for hours to days (Bliss and Lomo 1973). Following its initial discovery, LTP was subsequently found to be inducible at nearly all stages of hippocampal synaptic transmission.

At most synapses, LTP follows Hebb's synaptic learning rules in that it requires strong synaptic activity that is able to drive spike firing in the postsynaptic cells (Bliss and Collingridge 1993; Bliss et al. 2014). The one exception is mossy fiber LTP from DG granules cells to CA3 pyramidal neurons, which is found in most studies to require only presynaptic activity with no requirement for action potential firing in the postsynaptic neuron (Nicoll and Malenka 1995). Tetanic stimulation of the SCs from CA3 pyramidal neurons also induces Hebbian LTP at the synapses these axons make onto other
CA3 pyramidal neurons (recurrent collaterals) as well as at their synapses with CA1 pyramidal neurons (Fig. 5A). In contrast, tetanic high-frequency stimulation (HFS) does not normally induce LTP in the classical Hebbian sense at the SC synapses onto CA2 pyramidal neurons (Zhao et al. 2007) because of their strong expression of the G-protein regulatory protein RGS14 (Lee et al. 2010) and enhanced $\mathrm{Ca}^{2+}$ pump activity (Simons et al. 2009). However, a form of LTP was recently described at SC $\rightarrow$ CA2 synapses that relies on suppression of feedforward inhibition (see below) (Piskorowski and Chevaleyre 2013). Finally, LTP can also be induced by tetanic stimulation of the direct EC inputs to CA1 and CA2, although the extent of LTP onto CA1 is typically quite small. Thus, HFS LTP is a widespread form of homosynaptic activity-dependent plasticity found at all excitatory synapses throughout the hippocampal circuit.

Our understanding of the synaptic and molecular mechanisms underlying LTP has progressed greatly since its initial discovery. However, a number of fundamental questions concerning the basic properties of LTP, as well as the precise role that different forms of LTP play in learning and memory, remain unanswered.

The key characteristics of activity-dependent Hebbian LTP are established by the properties of the NMDARs, whose activation is critical for the induction of LTP at many synapses, including the SC $\rightarrow$ CA1 synapses (Collingridge et al. 1983). Fast excitatory synapses rely on two classes of ionotropic glutamate receptors, the NMDARs and $\alpha$-amino-3-hydroxy5-methyl-4-isoxazolepropionic acid receptors (AMPARs). NMDARs differ from most ionotropic ligand-gated channels (including the AMPARs), in that they require membrane depolarization in addition to glutamate neurotransmitter to function. At typical negative resting potentials, the pore of the NMDAR is blocked by an $\mathrm{Mg}^{2+}$ ion. As a result, basal synaptic transmission normally relies on activation of the AMPARs. However, when presynaptic activity is coupled with strong postsynaptic depolarization, such as during tetanic stimulation, the NMDARs are relieved from 
their $\mathrm{Mg}^{2+}$ blockade through electrostatic repulsion. NMDARs are also distinguished from most AMPARs by their high permeability to $\mathrm{Ca}^{2+}$, which acts as a second messenger inside cells to activate a number of downstream signaling cascades. As a result, NMDAR activation during strong synaptic stimulation causes a rise in intracellular $\mathrm{Ca}^{2+}$ levels, which leads to activation of the $\mathrm{Ca}^{2+}$-calmodulin-dependent protein kinase II (CaMKII), a step critical for the induction of LTP (Malenka et al. 1989; Malinow et al. 1989).

A major question that has dominated the field is whether LTP results from a presynaptic change, involving an increase in glutamate release, or a postsynaptic change, resulting from an increase in the postsynaptic response to glutamate, or a coordinated change in presynaptic and postsynaptic properties. This has led to a lively controversy in the field that remains to date. A number of investigators state the case that LTP is largely postsynaptic, resulting from the insertion of AMPARs into the postsynaptic membrane (Huganir and Nicoll 2013; Nicoll and Roche 2013). Others argue that LTP is largely presynaptic (Enoki et al. 2009) or is a mixture of distinct pre and postsynaptic processes (Bliss et al. 2014).

Much of the controversy likely results from the fact that LTP is not a unitary phenomenon (Mayford et al. 2012). Rather a neuron can express multiple forms of long-lasting synaptic plasticity that differ in the pattern of activity needed for their induction, underlying molecular mechanism, time scale of onset and duration, and role in learning and memory (Fig. 5). The behaviorally linked activity state and the coupled molecular tuning of upstream inputs and downstream targets will also determine the ability of a particular circuit to serve as a substrate for plasticity, a process termed metaplasticity (Abraham and Tate 1997), and thereby allow the modulation of information flow. One clear indication of this diversity is provided by the observation that certain forms of LTP that appear to have a presynaptic locus of expression do not require activation of NMDARs but are primarily mediated by $\mathrm{Ca}^{2+}$ influx through voltage-gated calcium channels (Grover and
Teyler 1990). Another important finding is that deletion of the GluR1 AMPA receptor subunit blocks LTP induced by tetanic stimulation but only partially inhibits LTP induced by theta burst stimulation (Hoffman et al. 2002) and has little effect on synaptic potentiation during spike-timing-dependent plasticity (STDP) (Frey et al. 2009), a form of plasticity induced by the pairing of an EPSP with a postsynaptic action potential (Markram et al. 1997).

Another important distinction among different forms of synaptic plasticity lies in the time course and duration of the change in synaptic efficacy. LTP in the hippocampus has both early and late phases. For example, stimulation of SC inputs using one train of tetanic stimulation (at $100 \mathrm{~Hz}$ for $1 \mathrm{sec}$ ) produces an early phase of potentiation (E-LTP) that lasts for 1 to $3 \mathrm{~h}$ and does not require protein synthesis. Stimulation with four or more identical trains spaced several minutes apart recruits a late phase of potentiation (L-LTP), which can last for $24 \mathrm{~h}$ or more (Huang and Kandel 1994). Unlike E-LTP, L-LTP requires new protein synthesis and also depends on the activation of protein kinase A (PKA) (Frey et al. 1993; Abel et al. 1997) through the action of modulatory transmitters, such as DA (Huang and Kandel 1995). The role of L-LTP has been investigated genetically using mice that express a mutant gene that blocks the catalytic subunit of PKA, or carry an inhibitory mutation in the CREB-1 gene. Both lines of mice have a serious defect in long-term spatial memory and similar defects in LTP. The early phase is normal but the late phase is blocked, providing evidence linking the phases of LTP to the phases of memory storage (Silva et al. 1992; Abel et al. 1997; Bourtchouladze et al. 1998). Theoretical studies suggest that the expression of different temporal phases of LTP enables the stability of long-term memory traces as new memories are encoded through ongoing plastic changes in synaptic function (Fusi et al. 2005).

\section{Long-Term Depression}

The presence of LTP raises the prospect that synapses may become saturated during the life- 
time of an animal, and thus no longer able to encode new memories. This potential problem is averted by the antagonistic processes of depotentiation and long-term depression (LTD) (Bear and Abraham 1996), which can be induced by prolonged periods $(5-15 \mathrm{~min})$ of low frequency stimulation $(1-5 \mathrm{~Hz})$. Depotentiation refers to the reversal of LTP seen when low frequency stimulation is delivered shortly after induction of LTP. LTD is induced by low frequency stimulation in the absence of prior induction of LTP. Similar to LTP, there are also different forms of LTD. One prominent form requires activation of NMDARs and an influx of postsynaptic $\mathrm{Ca}^{2+}$, similar to NMDAR-dependent LTP (Bear and Abraham 1996). Another form of LTD requires activation of metabotropic glutamate receptors (Luscher and Huber 2010).

How can $\mathrm{Ca}^{2+}$ influx through NMDARs differentially trigger LTP versus LTD? The answer seems to depend on the magnitude and duration of the postsynaptic $\mathrm{Ca}^{2+}$ signal, with a large elevation in $\mathrm{Ca}^{2+}$ triggering LTP and a more long-lasting but low $\mathrm{Ca}^{2+}$ signal resulting in LTD (Neveu and Zucker 1996). These differences may reflect the distinct molecular mechanisms of LTP versus LTD, with LTP requiring activation of CaMKII, whereas LTD requires activation of the calcium-calmodulin-dependent phosphatase calcineurin (Mulkey et al. 1994), which is activated by lower levels of $\mathrm{Ca}^{2+}$.

\section{Spike-Timing-Dependent Plasticity}

The relevance of LTP for learning and memory has been questioned because of the nonphysiological, prolonged high-frequency tetanic stimulation required for its induction. However, a form of long-lasting synaptic potentiation can be induced by more physiologically relevant patterns of stimulation through STDP, involving the pairing of a relatively weak presynaptic stimulus with the firing of a postsynaptic action potential. Moreover the potentiation during STDP shows a strict dependence on the timing of the EPSP and spike (Fig. 5B) (Magee and Johnston 1997; Markram et al. 1997). If the postsynaptic spike follows the presynaptic ac- tion potential by $10 \mathrm{msec}$, a synapse is maximally potentiated, conforming to a Hebbian learning rule. In contrast, if the spike precedes the presynaptic stimulus, the synapse becomes depressed. If the presynaptic and postsynaptic cells fire action potentials separated by $40 \mathrm{msec}$ or more, there is no change in the synaptic strength. This timing dependence is consistent with the properties of the NMDARs, where the firing of a postsynaptic spike following, but not preceding, glutamate release will be able to relieve $\mathrm{Mg}^{2+}$ block, thereby enabling $\mathrm{Ca}^{2+}$ influx and the induction of plasticity. Thus, STDP provides a mechanism for strengthening or weakening synapses depending on the correlation or anticorrelation between presynaptic and postsynaptic firing. Similar to LTP and LTD, STDP also requires activation of NMDARs. However, as mentioned above, STDP is likely to recruit distinct downstream mechanisms from tetanus-induced LTP.

\section{Role of LTP and LTD in Learning and Memory}

The properties of NMDA-dependent synaptic plasticity provide an attractive cellular mechanism for forming learned associations. However, it has been significantly more difficult to prove direct causative links between LTP and behavior. The first correlation between LTP and spatial memory was provided by the demonstration that pharmacological blockade of NMDARs prevents spatial reference memory formation, assessed by the MWM (Morris et al. 1986). Importantly, blockade of the NMDARs did not impair the ability of an animal to learn to swim to the platform when it is visible, a task that does not require the hippocampus. Pharmacological blockade of NMDARs also decreases the stability of place fields across two recording sessions separated by $24 \mathrm{~h}$ (Kentros et al. 1998).

Subsequent studies showed that NMDAR blockade does not prevent memory formation in the water maze if rats are pretrained on the task in a different spatial setting (Bannerman et al. 1995; Saucier and Cain 1995). This suggests that NMDAR-independent mechanisms can suffice for learning spatial associations under some conditions. Whether the spatial learn- 
ing occurs through non-NMDAR-dependent forms of LTP or through another mechanism is not known.

Genetic evidence linking LTP in the CA1 region of the hippocampus with learning was again provided by experiments that rely on manipulation of NMDAR function. Mice lacking an essential NMDAR subunit (NR1) in the CA1 region (Tsien et al. 1996) show a loss of tetanusinduced LTP at the SC $\rightarrow$ CA1 pathway and have a profound deficit in the MWM. However, subsequent NR1 knockout-based studies have raised questions about these initial conclusions (Bannerman et al. 2014). First, the initial NR1 deletion mouse line was found to have a loss of NR1 outside the hippocampus. Furthermore, a second transgenic mouse line in which deletion of NR1 was indeed restricted to DG and CA1 showed no deficit in spatial reference memory, whereas spatial working memory performance was impaired (Bannerman et al. 2012). Interestingly, these mice did show difficulties in relearning a new location of the MWM platform after initial training. This result has led to the suggestion that hippocampal NMDAR-dependent LTP is necessary for resolving conflicts between stored information and the current sensory context rather than for encoding paired associative memories (Bannerman et al. 2014).

It is also important to realize that the establishment of a link between NMDARs and certain hippocampal-dependent memory tasks does not necessarily imply that the memory formation results from NMDAR-dependent LTP. This is because NMDARs subserve a number of functions apart from the induction of LTP, including generation of a late phase of the glutamatergic EPSP and regenerative dendritic voltage signals termed NMDAR spikes (Golding et al. 1999, 2002; Schiller et al. 2000). Conversely, the finding that pharmacological blockade or genetic deletion of the NMDAR does not alter learning and memory in certain tasks suggests a potential role of non-NMDAR-dependent forms of LTP.

An important line of evidence linking LTP to hippocampal learning and memory comes from in vivo extracellular recording experiments during learning behaviors. For example, one study (Whitlock et al. 2006) found that one-trial inhibitory avoidance learning produces an enhancement in synaptic responses evoked by electrical stimulation of $\mathrm{SC} \rightarrow \mathrm{CA} 1$ pyramidal neuron inputs. Moreover, learning behaviors brought about the same changes in AMPAR phosphorylation and membrane trafficking as seen during induction of LTP by tetanic stimulation.

Although less thoroughly examined than LTP, several lines of evidence suggest the importance of LTD in both learning and its extinction. Pharmacological blockade of NMDAR-dependent hippocampal LTD was found to impair consolidation of long-term spatial memory in the MWM (Ge et al. 2010). Furthermore, Kemp and Manahan-Vaughan (2004) showed an enhanced induction of CA1 LTD by low-frequency stimulation when rats explored novel objects in a new environment. Links between mGluRdependent hippocampal LTD and object-place learning was provided by a recent study ( $\mathrm{Di}$ Prisco et al. 2014) in mice carrying a phosphorylation-deficient mutation of the translational factor EF2 $\alpha$.

Some of the best evidence linking LTP and LTD to learning and memory comes from studies in amygdala, in which the relatively simple circuitry and its role in well-established behavioral paradigms provide an important experimental advantage (McNally et al. 2011). Early studies showed that cued fear conditioning, in which animals learn to associate a tone with a shock, led to an LTP-like enhancement in the synaptic response both to the auditory conditioned stimulus recorded from the amygdala in vivo (Rogan et al. 1997) and to electrical stimulation of thalamic input to the amygdala in an in vitro slice preparation (McKernan and Shinnick-Gallagher 1997). Cued fear conditioning also occluded subsequent induction of LTP at corticoamygdala synapses in acute amygdala slices (Tsvetkov et al. 2002). Interestingly, a learned safety response in which an auditory stimulus signals the absence of aversive stimuli led to an LTD-like decrease in the synaptic response of lateral amygdala to the auditory cue (Rogan et al. 2005). Recent in vivo experiments using optogenetics to directly stimulate the corticothalamic auditory inputs to amygdala show 
that induction of LTD can suppress fear conditioning memory and that the subsequent induction of LTP can restore the fearful memory (Nabavi et al. 2014), providing some of the strongest evidence linking memory to plastic changes that enhance or diminish synaptic responses.

\section{Inhibitory Circuits in Plasticity, Learning, and} Memory

In addition to plastic changes at the excitatory synapses onto CA1 pyramidal neurons, a number of studies have now described activitydependent plastic changes in the inhibitory synapses these neurons receive. Several recent studies have begun to address the role of inhibition and inhibitory plasticity in learning and memory, as discussed next (see also the recent reviews by Kullmann et al. 2012; Wester and McBain 2014).

One prominent form of activity-dependent plasticity of inhibitory synaptic transmission is mediated by the endocannabinoid-signaling pathway (Castillo et al. 2012; Younts and Castillo 2014). Although endocannabinoids have been reported to contribute to LTD and LTP at excitatory SC synapses in some experimental paradigms (Ohno-Shosaku et al. 2002; Peterfi et al. 2012), the most prominent action of these signaling molecules involves the suppression of inhibition. This results from the presynaptic inhibition of GABA release caused by the binding of endocannabinoids to G-protein-coupled $\mathrm{CB} 1$ receptors present on presynaptic terminals of cholecystokinin-positive $\left(\mathrm{CCK}^{+}\right)$inhibitory neurons. Endocannabinoids were first found to mediate a short-lasting suppression of inhibition observed following strong postsynaptic depolarization of the CA1 pyramidal neuron (Wilson and Nicoll 2001). Later studies found that tetanic or theta burst stimulation of the SC pathway could induce an endocannabinoiddependent LTD of GABA release (Katona et al. 1999; Chevaleyre and Castillo 2003; Freund and Katona 2007). Interestingly, in addition to these stronger stimulation paradigms (Chevaleyre and Castillo 2003, 2004), endocannabinoid CB1R-mediated synaptic modulation can be induced by coincident recruitment of presynaptic inputs with subthreshold depolarizations and activation of mGluRs (Hashimotodani et al. 2007; Basu et al. 2013). Such endocannabinoid-mediated plasticity of inhibition can have a long-lasting effect to enhance the output of the excitatory CA1 circuit (see below) (Chevaleyre and Castillo 2004; Zhu and Lovinger 2007; Basu et al. 2013; Younts et al. 2013).

Several studies have used pharmacological and genetic approaches to address the role of CB1Rs in hippocampal-dependent memory behaviors. Unconditional deletion of the CB1R in mice results in heightened freezing responses to hippocampal-dependent CFC and an increased overgeneralization of fear memories to a strong unconditioned aversive stimulus. This behavioral effect was accompanied by an increase of LTP at the PP inputs to DG (Jacob et al. 2012). Evidence suggesting the importance of hippocampal CB1Rs comes from the finding that specific knockdown of these receptors in pyramidal cells and interneurons of mouse dorsal hippocampus both impairs associative learning during hippocampal-dependent trace eyeblink conditioning and reduces HFS-induced SC LTP (Madronal et al. 2012).

One surprising finding comes from a study showing that selective deletion of the CB1R from astrocytes impairs both in vivo LTD induced by the cannabinoid agonist THC as well as performance in a spatial working memory version of a MWM task (Han et al. 2012). This form of LTD also requires activation of NR2B subunit containing NMDARs and down-regulation of surface AMPARs. In contrast, selective deletion of the CB1R from cortical and hippocampal glutamatergic or GABAergic neurons produced little change in working memory or in vivo endocannabinoid-dependent LTD.

As described above, tetanic stimulation normally fails to elicit classical homosynaptic LTP at glutamatergic SC-CA2 pyramidal neuron synapses (Caruana et al. 2012). However, when inhibition is intact, high-frequency $10 \mathrm{~Hz}$ or theta-burst stimulation of CA3 inputs to CA2 can induce potentiation of information flow in this pathway. Such activity leads to a $\delta$-opioid- 
dependent LTD of GABAergic feedforward inhibition mediated by parvalbumin (PV) interneurons. The decreased inhibition results in a long-term enhancement of the ability of SC stimulation to excite the CA2 pyramidal neurons (Piskorowski and Chevaleyre 2013).

Neuromodulatory tuning of PV interneurons in the hippocampal CA1 region also occurs through the actions of oxytocin (Owen et al. 2013). This hormone enhances the spontaneous firing of bistratified and basket PV interneurons, leading to the suppression of spontaneous spiking activity in CA1 pyramidal neurons. At the same time, oxytocin decreases feedforward inhibition onto CA1 pyramidal neurons in response to activation of the SC inputs, likely a result of short-term synaptic depression of GABA release caused by the elevated spontaneous firing rate. The reduction in feedforward inhibition enhances the firing of synaptically evoked action potentials in CA1 pyramidal neurons. These dual actions of oxytocin to inhibit spontaneous pyramidal neuron firing, while enhancing net evoked synaptic excitation, greatly increase the signal to noise ratio in information transfer through the trisynaptic circuit.

Genetic silencing of PV interneurons in dorsal hippocampus results in a deficit in spatial working memory but does not impair longterm spatial memory (Fig. 4) (Murray et al. 2011). Although PV interneurons were silenced by targeted injections into the CA1 region of a viral vector expressing tetanus toxin, some of the behavioral changes may have resulted from expression of the toxin in the neighboring CA2 region, which has an unusually dense population of PV interneurons. Silencing PV interneurons also increases the firing rates of place cells within the place field and shifted spike timing in relation to spatially modulated theta phase; however, it does not affect their place-field size (Royer et al. 2012).

The oriens-lacunosum moleculare (OLM) subpopulation of SOM-expressing interneurons has also been shown to powerfully regulate memory encoding. These neurons are located in $\mathrm{SO}$ where they are recruited in a recurrent fashion by CA1 pyramidal neuron output and by subcortical cholinergic inputs. The OLM neu- rons send their axons to SLM where they powerfully inhibit the distal dendrites of CA1 pyramidal neurons, thereby suppressing the excitatory effects of the direct EC inputs to CA1. Activation of the OLM neurons by cholinergic inputs in response to a fearful stimulus (foot shock) has been found to be important for encoding of contextual fear conditioning (LovettBarron et al. 2014).

\section{Corticohippocampal Heterosynaptic Plasticity}

LTP and STDP are nonsupervised, homosynaptic Hebbian learning rules in which activity in a single class of excitatory synaptic inputs alters the efficacy of those same inputs. In contrast, cerebellar LTD (Ito 2001) represents a heterosynaptic supervised learning rule, in which activity in one set of excitatory synapses (climbing fibers), is thought to provide an error signal that induces plasticity (LTD) at another set of excitatory synapses (parallel fibers), which plays an important role in certain forms of motor learning. Might the complex and convergent set of cortical and hippocampal inputs to a CA1 pyramidal neuron also support activity-dependent heterosynaptic learning rules?

The fact that CA1 pyramidal neurons receive both weak direct sensory input from the $\mathrm{EC}$ and strong processed or mnemonic input from CA3 has led a number of groups to investigate the possible function of this dual input. Strong paired activation of the EC and SC inputs antagonizes the induction of HFS LTP at the SC inputs because the EC inputs produce a strong inhibitory response in the CA1 pyramidal neurons (Levy et al. 1998; Remondes and Schuman 2004). Other groups have found that stimulation of the SC pathway before PP activation can potentiate the propagation of the EC EPSP to the soma (Jarsky et al. 2005; Ang et al. 2006).

In contrast to the suppressive effect of EC input stimulation on SC LTP noted above, the pairing of a brief $100 \mathrm{~Hz}$ burst of four EC stimuli with a single SC stimulus at theta frequency $(5 \mathrm{~Hz})$ causes a small long-lasting potentiation in the SC pathway ( $25 \%$ increase) when the SC 
stimulus occurs within 70 msec of the end of the burst (Judge and Hasselmo 2004). Theta burst stimulation of the EC pathway alone can produce a slow, small $(20 \%-40 \%)$ potentiation of the SC pathway, with no change in the EC synaptic response (Han and Heinemann 2013). Simultaneous theta burst stimulation of the entorhinal cortex and SC inputs results in dendritic plateau potentials and a $30 \%$ to $60 \%$ LTP of the PP EPSP (Takahashi and Magee 2009).

One particularly interesting feature of the direct and trisynaptic corticohippocampal inputs to CA1 pyramidal neurons is that they are organized in a delay line architecture, in which information carried by the direct entorhinal cortex inputs arrive at CA1 pyramidal neurons some 15-20 msec before the arrival of information propagated through the trisynaptic path (Yeckel and Berger 1990). Our laboratory (Dudman et al. 2007) examined whether such a delay-line architecture might be used to implement a timing-dependent synaptic learning rule. The paired activation of the entorhinal cortex and SC inputs at a 20 msec delay interval (PP before SC) in hippocampal slices induces a surprisingly large $(100 \%-300 \%)$ potentiation of the SC synaptic response, without altering the entorhinal cortex-evoked response. In contrast, pairings at slightly different intervals (10 or $30 \mathrm{msec}$ ) or reversed timing (SC before entorhinal cortex) produced little or no long-lasting potentiation (Fig. 5C) (Dudman et al. 2007; Basu et al. 2013). This phenomenon was termed input timing-dependent plasticity (ITDP), (Dudman et al. 2007), by analogy to STDP.

ITDP shares key features with SC HFS LTP in that it requires $\mathrm{Ca}^{2+}$ influx through NMDARs and some postsynaptic depolarization (Dudman et al. 2007; Basu et al. 2013). It differs from LTP in that it does not require a large postsynaptic depolarization or CA1 action potential output. ITDP also requires activation of the mGluR1a metabotropic glutamate receptor and $\mathrm{IP}_{3}$ receptor-dependent $\mathrm{Ca}^{2+}$ release from internal stores (Dudman et al. 2007; Basu et al. 2013).

What is responsible for the large enhancement in synaptic transmission observed during ITDP? One of the unusual properties of ITDP is that it can be robustly induced when inhibition is intact. Indeed blockade of GABA receptors greatly reduces the magnitude of ITDP, indicating the importance of inhibitory synaptic transmission (Xu et al. 2012; Basu et al. 2013). Because the PSP generated in a CA1 pyramidal neuron in response to SC stimulation is determined by the overlapping SC EPSP and the feedforward IPSP, the enhanced depolarizing response during ITDP could result, in principle, from either an increase in the EPSP or a decrease in the feedforward IPSP. Our laboratory (Basu et al. 2013) approached this question by examining the EPSP and IPSP separately and found that ITDP results from both a long-lasting potentiation of the EPSP (E-LTP) and a long-lasting depression of the IPSP (I-LTD). Moreover, I-LTD was found to result from a selective decrease in perisomatic inhibition from CCK-expressing interneurons mediated by the release of endocannabinoids and the activation of CB1 G-protein-coupled receptors.

The fact that ITDP is highly tuned to the timing delay for propagation of information through the trisynaptic versus direct paths to CA1 pyramidal neurons suggests that it might be useful for assessing the salience of mnemonic information processed through DG and CA3 to the immediate sensory context encoded by EC inputs. A role for ITDP in learning and memory is consistent with the deficit in learned temporal associations seen on inactivation of LIII neurons in the MEC (Suh et al. 2011; Kitamura et al. 2014) and with the learning defects seen on deletion of the $\mathrm{CB} 1$ receptors described above. A possible role for ITDP in spatial coding is also suggested by its dependence on CCK inhibitory basket cells, which fire synchronously during spatially tuned theta activity at a phase that just precedes place-cell firing as the animal enters the corresponding place field (Klausberger et al. 2005). Endocannabinoid-dependent modulation of feedforward inhibition mediated by CCK interneurons may be a plausible way for the CA1 microcircuit to generate higher contrast for functionally linked pyramidal neuron ensembles in a use-dependent manner, such as during contextual or spatial coding. During sensory experience-driven associative learning, 
J. Basu and S.A. Siegelbaum

ITDP could be useful for the assignment of weights to previously stored hippocampal representations based on the online cortical sensory information stream.

\section{SUMMARY}

One of the most difficult problems in linking synaptic plasticity mechanisms to declarative memory is the sparse and distributed nature of the functionally linked circuits. How the various neural representations of the environment are modified with learning, the location of the critical sites of plasticity, and how these modified circuits are recruited to alter motor output during a behavioral memory task are still largely unclear. This makes interpreting the effects of a single type of pharmacological manipulation quite difficult. However, recent genetic-based approaches allowing the marking of neural assemblies activated by learning paradigms and reactivated during memory recall (Garner et al. 2012; Liu et al. 2012; Ramirez et al. 2013; Denny et al. 2014) offer an exciting approach for the identification and spatiotemporal dissection of the specific circuit elements that are involved in formation of specific memories.

Given that different forms of synaptic plasticity are tightly tuned to the temporal patterns of activation, defined circuit elements that participate in the induction or expression of specific forms of synaptic plasticity could be optogenetically manipulated during behavior to simulate how such temporal codes contribute to learning (Nabavi et al. 2014). Cell-type as well as compartment-specific in vivo functional imaging during learning behaviors will also provide glimpses of cellular dynamics, synapse strengthening or weakening as memories are formed in the live animal (Holtmaat et al. 2006; Lai et al. 2012; Donato et al. 2013; Ziv et al. 2013; Grienberger et al. 2014; Lovett-Barron et al. 2014). We expect that such advances will greatly enhance our understanding of how changes in information flow through the corticohippocampal circuit through both homosynaptic and heterosynaptic plasticity mechanisms contribute to hippocampal-dependent learning and memory.

\section{REFERENCES}

Abel T, Nguyen PV, Barad M, Deuel TA, Kandel ER, Bourtchouladze R. 1997. Genetic demonstration of a role for PKA in the late phase of LTP and in hippocampus-based long-term memory. Cell 88: 615-626.

Abraham WC, Tate WP. 1997. Metaplasticity: A new vista across the field of synaptic plasticity. Prog Neurobiol 52: 303-323.

Ahmed OJ, Mehta MR. 2009. The hippocampal rate code: Anatomy, physiology and theory. Trends Neurosci 32: 329-338.

Aihara T, Tsukada M, Crair MC, Shinomoto S. 1997. Stimulus-dependent induction of long-term potentiation in CA1 area of the hippocampus: Experiment and model. Hippocampus 7: 416-426.

Alarcon JM, Hodgman R, Theis M, Huang YS, Kandel ER, Richter JD. 2004. Selective modulation of some forms of Schaffer collateral-CA1 synaptic plasticity in mice with a disruption of the CPEB-1 gene. Learn Mem 11: $318-327$.

Amaral DG, Witter MP. 1989. The three-dimensional organization of the hippocampal formation: A review of anatomical data. Neuroscience 31: 571-591.

Ang CW, Carlson GC, Coulter DA. 2006. Massive and specific dysregulation of direct cortical input to the hippocampus in temporal lobe epilepsy. J Neurosci 26: 1185011856.

Arai A, Black J, Lynch G. 1994. Origins of the variations in long-term potentiation between synapses in the basal versus apical dendrites of hippocampal neurons. Hippocampus 4: 1-9.

Baimbridge KG, Miller JJ. 1982. Immunohistochemical localization of calcium-binding protein in the cerebellum hippocampal formation and olfactory bulb of the rat. Brain Res 245: 223-229.

Baimbridge KG, Miller JJ, Parkes CO. 1982. Calcium-binding protein distribution in the rat brain. Brain Res 239: 519-525.

Bannerman DM, Good MA, Butcher SP, Ramsay M, Morris RG. 1995. Distinct components of spatial learning revealed by prior training and NMDA receptor blockade. Nature 378: 182-186.

Bannerman DM, Bus T, Taylor A, Sanderson DJ, Schwarz I, Jensen V, Hvalby Ø, Rawlins JN, Seeburg PH, Sprengel R. 2012. Dissecting spatial knowledge from spatial choice by hippocampal NMDA receptor deletion. Nat Neurosci 15: 1153-1159.

Bannerman DM, Sprengel R, Sanderson DJ, McHugh SB, Rawlins JN, Monyer H, Seeburg PH. 2014. Hippocampal synaptic plasticity, spatial memory and anxiety. Nat Rev Neurosci 15: 181-192.

Bannister NJ, Larkman AU. 1995a. Dendritic morphology of CA1 pyramidal neurones from the rat hippocampus. I: Branching patterns. J Comp Neurol 360: 150-160.

Bannister NJ, Larkman AU. 1995b. Dendritic morphology of CA1 pyramidal neurones from the rat hippocam- 
pus. II: Spine distributions. J Comp Neurol 360: 161171.

Bartsch T, Döhring J, Rohr A, Jansen O, Deuschl G. 2011. CA1 neurons in the human hippocampus are critical for autobiographical memory, mental time travel, and autonoetic consciousness. Proc Natl Acad Sci 108: $17562-17567$

Basu J, Srinivas KV, Cheung SK, Taniguchi H, Huang ZJ, Siegelbaum SA. 2013. A cortico-hippocampal learning rule shapes inhibitory microcircuit activity to enhance hippocampal information flow. Neuron 79: 1208-1221.

Bear MF, Abraham WC. 1996. Long-term depression in hippocampus. Annu Rev Neurosci 19: 437-462.

Bethus I, Tse D, Morris RG. 2010. Dopamine and memory: Modulation of the persistence of memory for novel hippocampal NMDA receptor-dependent paired associates. J Neurosci 30: 1610-1618.

Bi GQ, Poo MM. 1998. Synaptic modifications in cultured hippocampal neurons: Dependence on spike timing, synaptic strength, and postsynaptic cell type. J Neurosci 18: 10464-10472.

Bjerknes TL, Moser EI, Moser MB. 2014. Representation of geometric borders in the developing rat. Neuron 82: $71-78$

Bliss TV, Collingridge GL. 1993. A synaptic model of memory: Long-term potentiation in the hippocampus. Nature 361: $31-39$.

Bliss TV, Lomo T. 1973. Long-lasting potentiation of synaptic transmission in the dentate area of the anaesthetized rabbit following stimulation of the perforant path. JPhysiol 232: $331-356$.

Bliss TV, Collingridge GL, Morris RG. 2014. Synaptic plasticity in health and disease: Introduction and overview. Philos Trans R Soc Lond B Biol Sci 369: 20130129.

Bonnevie T, Dunn B, Fyhn M, Hafting T, Derdikman D, Kubie JL, Roudi Y, Moser EI, Moser MB. 2013. Grid cells require excitatory drive from the hippocampus. $\mathrm{Nat} \mathrm{Neu}-$ rosci 16: 309-317.

Bourtchouladze R, Abel T, Berman N, Gordon R, Lapidus K, Kandel ER. 1998. Different training procedures recruit either one or two critical periods for contextual memory consolidation, each of which requires protein synthesis and PKA. Learn Mem 5: 365-374.

Braak H, Braak E. 1985. On areas of transition between entorhinal allocortex and temporal isocortex in the human brain. Normal morphology and lamina-specific pathology in Alzheimer's disease. Acta Neuropathol 68: 325-332.

Brun VH, Otnass MK, Molden S, Steffenach HA, Witter MP Moser MB, Moser EI. 2002. Place cells and place recognition maintained by direct entorhinal-hippocampal circuitry. Science 296: 2243-2246.

Brun VH, Leutgeb S, Wu HQ, Schwarcz R, Witter MP, Moser EI, Moser MB. 2008. Impaired spatial representation in CA1 after lesion of direct input from entorhinal cortex. Neuron 57: 290-302.

Burgess N, O’Keefe J. 1996. Neuronal computations underlying the firing of place cells and their role in navigation. Hippocampus 6: 749-762.

Bush D, Barry C, Burgess N. 2014. What do grid cells contribute to place cell firing? Trends Neurosci 37: 136-145.
Buzsaki G, Chrobak JJ. 1995. Temporal structure in spatially organized neuronal ensembles: A role for interneuronal networks. Curr Opin Neurobiol 5: 504-510.

Buzsaki G, Moser EI. 2013. Memory, navigation and theta rhythm in the hippocampal-entorhinal system. Nat Neurosci 16: $130-138$.

Caputi A, Melzer S, Michael M, Monyer H. 2013. The long and short of GABAergic neurons. Curr Opin Neurobiol 23: $179-186$.

Caruana DA, Alexander GM, Dudek SM. 2012. New insights into the regulation of synaptic plasticity from an unexpected place: Hippocampal area CA2. Learn Mem 19: 391-400.

Castillo PE, Younts TJ, Chavez AE, Hashimotodani Y. 2012. Endocannabinoid signaling and synaptic function. $\mathrm{Neu}$ ron 76: 70-81.

Chevaleyre V, Castillo PE. 2003. Heterosynaptic LTD of hippocampal GABAergic synapses: A novel role of endocannabinoids in regulating excitability. Neuron 38: 461-472.

Chevaleyre V, Castillo PE. 2004. Endocannabinoid-mediated metaplasticity in the hippocampus. Neuron 43: 871881.

Chevaleyre V, Siegelbaum SA. 2010. Strong CA2 pyramidal neuron synapses define a powerful disynaptic corticohippocampal loop. Neuron 66: 560-572.

Collingridge GL, Kehl SJ, McLennan H. 1983. Excitatory amino acids in synaptic transmission in the Schaffer collateral-commissural pathway of the rat hippocampus. $J$ Physiol 334: 33-46.

Corkin S. 2002. What's new with the amnesic patient H.M.? Nat Rev Neurosci 3: 153-160.

Cui Z, Gerfen CR, Young WS III. 2013. Hypothalamic and other connections with dorsal CA2 area of the mouse hippocampus. J Comp Neurol 521: 1844-1866.

Debanne D, Gahwiler BH, Thompson SM. 1998. Long-term synaptic plasticity between pairs of individual CA3 pyramidal cells in rat hippocampal slice cultures. J Physiol 507: $237-247$.

Denny CA, Kheirbek MA, Alba EL, Tanaka KF, Brachman RA, Laughman KB, Tomm NK, Turi GF, Losonczy A, Hen R. 2014. Hippocampal memory traces are differentially modulated by experience, time, and adult neurogenesis. Neuron 83: 189-201.

DeVito LM, Konigsberg R, Lykken C, Sauvage M, Young WS III, Eichenbaum H. 2009. Vasopressin $1 \mathrm{~b}$ receptor knockout impairs memory for temporal order. J Neurosci 29: 2676-2683.

Di Prisco GV, Huang W, Buffington SA, Hsu CC, Bonnen PE, Placzek AN, Sidrauski C, Krnjevic K, Kaufman RJ, Walter P, et al. 2014. Translational control of mGluRdependent long-term depression and object-place learning by eIF2 $\alpha$. Nat Neurosci 17: 1073-1082.

Dolleman-Van der Weel MJ, Lopes da Silva FH, Witter MP. 1997. Nucleus reuniens thalami modulates activity in hippocampal field CA1 through excitatory and inhibitory mechanisms. J Neurosci 17: 5640-5650.

Dolleman-van der Weel MJ, Morris RG, Witter MP. 2009. Neurotoxic lesions of the thalamic reuniens or mediodorsal nucleus in rats affect non-mnemonic aspects of watermaze learning. Brain Struct Funct 213: 329-342. 
J. Basu and S.A. Siegelbaum

Donato F, Rompani SB, Caroni P. 2013. Parvalbumin-expressing basket-cell network plasticity induced by experience regulates adult learning. Nature 504: 272-276.

Dong Z, Han H, Cao J, Zhang X, Xu L. 2008. Coincident activity of converging pathways enables simultaneous long-term potentiation and long-term depression in hippocampal CA1 network in vivo. PLoS ONE 3: e2848.

Dong S, Rogan SC, Roth BL. 2010. Directed molecular evolution of DREADDs: A generic approach to creating next-generation RASSLs. Nat Protoc 5: 561-573.

Dougherty KA, Nicholson DA, Diaz L, Buss EW, Neuman KM, Chetkovich DM, Johnston D. 2013. Differential expression of HCN subunits alters voltage-dependent gating of h-channels in CA1 pyramidal neurons from dorsal and ventral hippocampus. J Neurophysiol 109: 1940-1953.

Drew LJ, Fusi S, Hen R. 2013. Adult neurogenesis in the mammalian hippocampus: Why the dentate gyrus? Learn Mem 20: 710-729.

Dudman JT, Tsay D, Siegelbaum SA. 2007. A role for synaptic inputs at distal dendrites: Instructive signals for hippocampal long-term plasticity. Neuron 56: 866-879.

Duncan K, Ketz N, Inati SJ, Davachi L. 2012. Evidence for area $\mathrm{CAl}$ as a match/mismatch detector: A high-resolution fMRI study of the human hippocampus. Hippocampus 22: $389-398$.

Enoki R, Hu YL, Hamilton D, Fine A. 2009. Expression of long-term plasticity at individual synapses in hippocampus is graded, bidirectional, and mainly presynaptic: Optical quantal analysis. Neuron 62: 242-253.

Fanselow MS, Dong HW. 2010. Are the dorsal and ventral hippocampus functionally distinct structures? Neuron 65: 7-19.

Freund TF, Katona I. 2007. Perisomatic inhibition. Neuron 56: $33-42$.

Frey U, Huang YY, Kandel ER. 1993. Effects of cAMP simulate a late stage of LTP in hippocampal CA1 neurons. Science 260: 1661-1664.

Frey MC, Sprengel R, Nevian T. 2009. Activity pattern-dependent long-term potentiation in neocortex and hippocampus of GluA1 (GluR-A) subunit-deficient mice. J Neurosci 29: 5587-5596.

Fuentealba P, Begum R, Capogna M, Jinno S, Marton LF, Csicsvari J, Thomson A, Somogyi P, Klausberger T. 2008. Ivy cells: A population of nitric-oxide-producing, slowspiking GABAergic neurons and their involvement in hippocampal network activity. Neuron 57: 917-929.

Fusi S, Drew PJ, Abbott LF. 2005. Cascade models of synaptically stored memories. Neuron 45: 599-611.

Fyhn M, Molden S, Witter MP, Moser EI, Moser MB. 2004. Spatial representation in the entorhinal cortex. Science 305: $1258-1264$

Garner AR, Rowland DC, Hwang SY, Baumgaertel K, Roth BL, Kentros C, Mayford M. 2012. Generation of a synthetic memory trace. Science 335: 1513-1516.

Ge Y, Dong Z, Bagot RC, Howland JG, Phillips AG, Wong TP, Wang YT. 2010. Hippocampal long-term depression is required for the consolidation of spatial memory. Proc Natl Acad Sci 107: 16697-16702.

Golding NL, Jung HY, Mickus T, Spruston N. 1999. Dendritic calcium spike initiation and repolarization are con- trolled by distinct potassium channel subtypes in CA1 pyramidal neurons. J Neurosci 19: 8789-8798.

Golding NL, Staff NP, Spruston N. 2002. Dendritic spikes as a mechanism for cooperative long-term potentiation. Nature 418: 326-331.

Goshen I, Brodsky M, Prakash R, Wallace J, Gradinaru V, Ramakrishnan C, Deisseroth K. 2011. Dynamics of retrieval strategies for remote memories. Cell 147: 678689.

Grienberger C, Chen X, Konnerth A. 2014. NMDA receptordependent multidendrite $\mathrm{Ca}^{2+}$ spikes required for hippocampal burst firing in vivo. Neuron 81: 1274-1281.

Grover LM, Teyler TJ. 1990. Two components of long-term potentiation induced by different patterns of afferent activation. Nature 347: 477-479.

Hafting T, Fyhn M, Molden S, Moser MB, Moser EI. 2005. Microstructure of a spatial map in the entorhinal cortex. Nature 436: 801-806.

Haglund L, Swanson LW, Kohler C. 1984. The projection of the supramammillary nucleus to the hippocampal formation: An immunohistochemical and anterograde transport study with the lectin PHA-L in the rat. J Comp Neurol 229: $171-185$.

Han EB, Heinemann SF. 2013. Distal dendritic inputs control neuronal activity by heterosynaptic potentiation of proximal inputs. J Neurosci 33: 1314-1325.

Han J, Kesner P, Metna-Laurent M, Duan T, Xu L, Georges F, Koehl M, Abrous DN, Mendizabal-Zubiaga J, Grandes P, et al. 2012. Acute cannabinoids impair working memory through astroglial CB1 receptor modulation of hippocampal LTD. Cell 148: 1039-1050.

Hashimotodani Y, Ohno-Shosaku T, Kano M. 2007. $\mathrm{Ca}^{2+}$. assisted receptor-driven endocannabinoid release: Mechanisms that associate presynaptic and postsynaptic activities. Curr Opin Neurobiol 17: 360-365.

Hebb DO. 1949. The organization of behavior. Wiley, New York.

Henriksen EJ, Colgin LL, Barnes CA, Witter MP, Moser MB, Moser EI. 2010. Spatial representation along the proximodistal axis of CA1. Neuron 68: 127-137.

Hirayasu Y, Wada JA. 1992. N-methyl-D-aspartate injection into the massa intermedia facilitates development of limbic kindling in rats. Epilepsia 33: 965-970.

Hitti FL, Siegelbaum SA. 2014. The hippocampal CA2 region is essential for social memory. Nature 508: 88-92.

Hoffman DA, Sprengel R, Sakmann B. 2002. Molecular dissection of hippocampal theta-burst pairing potentiation. Proc Natl Acad Sci 99: 7740-7745.

Holtmaat A, Wilbrecht L, Knott GW, Welker E, Svoboda K. 2006. Experience-dependent and cell-type-specific spine growth in the neocortex. Nature 441: 979-983.

Huang YY, Kandel ER. 1994. Recruitment of long-lasting and protein kinase A-dependent long-term potentiation in the CA1 region of hippocampus requires repeated tetanization. Learn Mem 1: 74-82.

Huang YY, Kandel ER. 1995. D1/D5 receptor agonists induce a protein synthesis-dependent late potentiation in the CA1 region of the hippocampus. Proc Natl Acad Sci 92: $2446-2450$.

Huganir RL, Nicoll RA. 2013. AMPARs and synaptic plasticity: The last 25 years. Neuron 80: 704-717. 
Igarashi KM, Lu L, Colgin LL, Moser MB, Moser EI. 2014 Coordination of entorhinal-hippocampal ensemble activity during associative learning. Nature 510: 143-147.

Ishikawa A, Nakamura S. 2006. Ventral hippocampal neurons project axons simultaneously to the medial prefrontal cortex and amygdala in the rat. $J$ Neurophysiol 96: 2134-2138.

Ishizuka N, Weber J, Amaral DG. 1990. Organization of intrahippocampal projections originating from $\mathrm{CA} 3 \mathrm{py}-$ ramidal cells in the rat. J Comp Neurol 295: 580-623.

Ito M. 2001. Cerebellar long-term depression: Characterization, signal transduction, and functional roles. Physiol Rev 81: 1143-1195.

Ito HT, Schuman EM. 2007. Frequency-dependent gating of synaptic transmission and plasticity by dopamine. Front Neural Circuits 1: 1.

Jacob W, Marsch R, Marsicano G, Lutz B, Wotjak CT. 2012. Cannabinoid CB1 receptor deficiency increases contextual fear memory under highly aversive conditions and long-term potentiation in vivo. Neurobiol Learn Mem 98: $47-55$.

Jarsky T, Roxin A, Kath WL, Spruston N. 2005. Conditional dendritic spike propagation following distal synaptic activation of hippocampal CA1 pyramidal neurons. Nat Neurosci 8: 1667-1676.

Jarsky T, Mady R, Kennedy B, Spruston N. 2008. Distribution of bursting neurons in the CAl region and the subiculum of the rat hippocampus. J Comp Neurol 506: 535547.

Jay TM. 2003. Dopamine: A potential substrate for synaptic plasticity and memory mechanisms. Prog Neurobiol 69: 375-390.

Jinno S, Klausberger T, Marton LF, Dalezios Y, Roberts JD, Fuentealba P, Bushong EA, Henze D, Buzsaki G, Somogyi P. 2007. Neuronal diversity in GABAergic long-range projections from the hippocampus. J Neurosci 27: 8790 8804.

Judge SJ, Hasselmo ME. 2004. Theta rhythmic stimulation of stratum lacunosum-moleculare in rat hippocampus contributes to associative LTP at a phase offset in stratum radiatum. J Neurophysiol 92: 1615-1624.

Jung MW, Wiener SI, McNaughton BL. 1994. Comparison of spatial firing characteristics of units in dorsal and ventral hippocampus of the rat. J Neurosci 14: 7347-7356.

Katona I, Sperlagh B, Sik A, Kafalvi A, Vizi ES, Mackie K, Freund TF. 1999. Presynaptically located CB1 cannabinoid receptors regulate GABA release from axon terminals of specific hippocampal interneurons. J Neurosci 19: 4544-4558.

Keinath AT, Wang ME, Wann EG, Yuan RK, Dudman JT, Muzzio IA. 2014. Precise spatial coding is preserved along the longitudinal hippocampal axis. Hippocampus 24: 1533-1543.

Kemp A, Manahan-Vaughan D. 2004. Hippocampal longterm depression and long-term potentiation encode different aspects of novelty acquisition. Proc Natl Acad Sci 101: 8192-8197.

Kentros C, Hargreaves E, Hawkins RD, Kandel ER, Shapiro M, Muller RV. 1998. Abolition of long-term stability of new hippocampal place cell maps by NMDA receptor blockade. Science 280: 2121-2126.
Kheirbek MA, Drew LJ, Burghardt NS, Costantini DO, Tannenholz L, Ahmari SE, Zeng H, Fenton AA, Hen R. 2013. Differential control of learning and anxiety along the dorsoventral axis of the dentate gyrus. Neuron 77: $955-$ 968.

Kim Y, Spruston N. 2012. Target-specific output patterns are predicted by the distribution of regular-spiking and bursting pyramidal neurons in the subiculum. Hippocampus 22: 693-706.

Kiss J, Csaki A, Bokor H, Shanabrough M, Leranth C. 2000. The supramammillo-hippocampal and supramammilloseptal glutamatergic/aspartatergic projections in the rat: A combined $\left[{ }^{3} \mathrm{H}\right]$ D-aspartate autoradiographic and immunohistochemical study. Neuroscience 97: 657-669.

Kitamura T, Pignatelli M, Suh J, Kohara K, Yoshiki A, Abe K, Tonegawa S. 2014. Island cells control temporal association memory. Science 343: 896-901.

Klausberger T, Somogyi P. 2008. Neuronal diversity and temporal dynamics: The unity of hippocampal circuit operations. Science 321: 53-57.

Klausberger T, Marton LF, O’Neill J, Huck JH, Dalezios Y, Fuentealba P, Suen WY, Papp E, Kaneko T, Watanabe M, et al. 2005. Complementary roles of cholecystokinin- and parvalbumin-expressing GABAergic neurons in hippocampal network oscillations. J Neurosci 25: 9782-9793.

Kohara K, Pignatelli M, Rivest AJ, Jung HY, Kitamura T, Suh J, Frank D, Kajikawa K, Mise N, Obata Y, et al. 2014. Cell type-specific genetic and optogenetic tools reveal hippocampal CA2 circuits. Nat Neurosci 17: 269-279.

Kraus BJ, Robinson RJ II, White JA, Eichenbaum H, Hasselmo ME. 2013. Hippocampal "time cells": Time versus path integration. Neuron 78: 1090-1101.

Kullmann DM, Moreau AW, Bakiri Y, Nicholson E. 2012. Plasticity of inhibition. Neuron 75: 951-962.

Lai CS, Franke TF, Gan WB. 2012. Opposite effects of fear conditioning and extinction on dendritic spine remodelling. Nature 483: 87-91.

Langston RF, Ainge JA, Couey JJ, Canto CB, Bjerknes TL, Witter MP, Moser EI, Moser MB. 2010. Development of the spatial representation system in the rat. Science 328: 1576-1580.

Lee SE, Simons SB, Heldt SA, Zhao M, Schroeder JP, Vellano CP, Cowan DP, Ramineni S, Yates CK, Feng Y, et al. 2010 RGS14 is a natural suppressor of both synaptic plasticity in CA2 neurons and hippocampal-based learning and memory. Proc Natl Acad Sci 107: 16994-16998.

Lee SH, Marchionni I, Bezaire M, Varga C, Danielson N, Lovett-Barron M, Losonczy A, Soltesz I. 2014. Parvalbumin-positive basket cells differentiate among hippocampal pyramidal cells. Neuron 82: 1129-1144.

Lein ES, Callaway EM, Albright TD, Gage FH. 2005. Redefining the boundaries of the hippocampal CA2 subfield in the mouse using gene expression and 3-dimensional reconstruction. J Comp Neurol 485: 1-10.

Lemon N, Manahan-Vaughan D. 2006. Dopamine $D_{1} / D_{5}$ receptors gate the acquisition of novel information through hippocampal long-term potentiation and long-term depression. J Neurosci 26: 7723-7729.

Leutgeb JK, Leutgeb S, Moser MB, Moser EI. 2007. Pattern separation in the dentate gyrus and CA3 of the hippocampus. Science 315: 961-966. 
J. Basu and S.A. Siegelbaum

Levy WB, Desmond NL, Zhang DX. 1998. Perforant path activation modulates the induction of long-term potentiation of the Schaffer collateral-hippocampal CA1 response: Theoretical and experimental analyses. Learn Mem 4: 510-518.

Lisman JE, Grace AA. 2005. The hippocampal-VTA loop: Controlling the entry of information into long-term memory. Neuron 46: 703-713.

Liu X, Ramirez S, Pang PT, Puryear CB, Govindarajan A, Deisseroth K, Tonegawa S. 2012. Optogenetic stimulation of a hippocampal engram activates fear memory recall. Nature 484: 381-385.

Lorente de Nó R. 1934. Studies on the structure of the cerebral cortex. II: Continuation of the study of the ammonic system. J Psychol Neurol 46: 113-177.

Lovett-Barron M, Kaifosh P, Kheirbek MA, Danielson N, Zaremba JD, Reardon TR, Turi GF, Hen R, Zemelman BV, Losonczy A. 2014. Dendritic inhibition in the hippocampus supports fear learning. Science 343: 857-863.

Luscher C, Huber KM. 2010. Group 1 mGluR-dependent synaptic long-term depression: Mechanisms and implications for circuitry and disease. Neuron 65: 445-459.

Macdonald CJ, Carrow S, Place R, Eichenbaum H. 2013. Distinct hippocampal time cell sequences represent odor memories in immobilized rats. J Neurosci 33: $14607-14616$

Madronal N, Gruart A, Valverde O, Espadas I, Moratalla R, Delgado-Garcia JM. 2012. Involvement of cannabinoid CB1 receptor in associative learning and in hippocampal CA3-CA1 synaptic plasticity. Cereb Cortex 22: 550-566.

Magee JC, Johnston D. 1997. A synaptically controlled, associative signal for Hebbian plasticity in hippocampal neurons. Science 275: 209-213.

Magloczky Z, Acsady L, Freund TF. 1994. Principal cells are the postsynaptic targets of supramammillary afferents in the hippocampus of the rat. Hippocampus 4: 322-334.

Malenka RC, Kauer JA, Perkel DJ, Mauk MD, Kelly PT, Nicoll RA, Waxham MN. 1989. An essential role for postsynaptic calmodulin and protein kinase activity in longterm potentiation. Nature 340: 554-557.

Malinow R, Schulman H, Tsien RW. 1989. Inhibition of postsynaptic PKC or CaMKII blocks induction but not expression of LTP. Science 245: 862-866.

Markram H, Lubke J, Frotscher M, Sakmann B. 1997. Regulation of synaptic efficacy by coincidence of postsynaptic APs and EPSPs. Science 275: 213-215.

Mayford M, Siegelbaum SA, Kandel ER. 2012. Synapses and memory storage. Cold Spring Harb Perspect Biol 4: a005751.

McKernan MG, Shinnick-Gallagher P. 1997. Fear conditioning induces a lasting potentiation of synaptic currents in vitro. Nature 390: 607-611.

McNally GP, Johansen JP, Blair HT. 2011. Placing prediction into the fear circuit. Trends Neurosci 34: 283-292.

Megias A, Martinez-Senac MM, Delgado J, Saborido A. 2001. Regulation of transverse tubule ecto-ATPase activity in chicken skeletal muscle. Biochem J 353: 521-529.

Melzer S, Michael M, Caputi A, Eliava M, Fuchs EC, Whittington MA, Monyer H. 2012. Long-range-projecting GABAergic neurons modulate inhibition in hippocampus and entorhinal cortex. Science 335: 1506-1510.
Mizuseki K, Sirota A, Pastalkova E, Buzsaki G. 2009. Theta oscillations provide temporal windows for local circuit computation in the entorhinal-hippocampal loop. $\mathrm{Neu}$ ron 64: $267-280$

Mizuseki K, Diba K, Pastalkova E, Buzsaki G. 2011. Hippocampal CA1 pyramidal cells form functionally distinct sublayers. Nat Neurosci 14: 1174-1181.

Morris RG. 2013. NMDA receptors and memory encoding. Neuropharmacology 74: 32-40.

Morris RG, Hagan JJ, Rawlins JN. 1986. Allocentric spatial learning by hippocampectomised rats: A further test of the "spatial mapping" and "working memory" theories of hippocampal function. Q J Exp Psychol B 38: 365-395.

Morris RG, Steele RJ, Bell JE, Martin SJ. 2013. N-methyl-Daspartate receptors, learning and memory: Chronic intraventricular infusion of the NMDA receptor antagonist D-AP5 interacts directly with the neural mechanisms of spatial learning. Eur J Neurosci 37: 700-717.

Mulkey RM, Endo S, Shenolikar S, Malenka RC. 1994. Involvement of a calcineurin/inhibitor-1 phosphatase cascade in hippocampal long-term depression. Nature 369: $486-488$.

Murray AJ, Sauer JF, Riedel G, McClure C, Ansel L, Cheyne L, Bartos M, Wisden W, Wulff P. 2011. Parvalbumin-positive CA1 interneurons are required for spatial working but not for reference memory. Nat Neurosci 14: 297-299.

Nabavi S, Fox R, Proulx CD, Lin JY, Tsien RY, Malinow R. 2014. Engineering a memory with LTD and LTP. Nature 511: 348-352.

Naber PA, Lopes da Silva FH, Witter MP. 2001. Reciprocal connections between the entorhinal cortex and hippocampal fields $\mathrm{CA} 1$ and the subiculum are in register with the projections from CA1 to the subiculum. Hippocampus 11: 99-104.

Nakashiba T, Young JZ, McHugh TJ, Buhl DL, Tonegawa S. 2008. Transgenic inhibition of synaptic transmission reveals role of CA3 output in hippocampal learning. Science 319: $1260-1264$

Nakashiba T, Cushman JD, Pelkey KA, Renaudineau S, Buhl DL, McHugh TJ, Rodriguez Barrera V, Chittajallu R, Iwamoto KS, McBain CJ, et al. 2012. Young dentate granule cells mediate pattern separation, whereas old granule cells facilitate pattern completion. Cell 149: 188-201.

Nakazawa K, Quirk MC, Chitwood RA, Watanabe M, Yeckel MF, Sun LD, Kato A, Carr CA, Johnston D, Wilson MA, et al. 2002. Requirement for hippocampal CA3 NMDA receptors in associative memory recall. Science 297: $211-$ 218.

Neveu D, Zucker RS. 1996. Postsynaptic levels of $\left[\mathrm{Ca}^{2+}\right]_{i}$ needed to trigger LTD and LTP. Neuron 16: 619-629.

Nicoll RA, Malenka RC. 1995. Contrasting properties of two forms of long-term potentiation in the hippocampus. Nature 377: 115-118.

Nicoll RA, Roche KW. 2013. Long-term potentiation: Peeling the onion. Neuropharmacology 74: 18-22.

Nielsen JV, Blom JB, Noraberg J, Jensen NA. 2010. Zbtb20induced CA1 pyramidal neuron development and area enlargement in the cerebral midline cortex of mice. Cereb Cortex 20: 1904-1914. 
Nishiyama M, Hong K, Mikoshiba K, Poo MM, Kato K. 2000. Calcium stores regulate the polarity and input specificity of synaptic modification. Nature 408: 584-588.

Ochiishi T, Saitoh Y, Yukawa A, Saji M, Ren Y, Shirao T, Miyamoto H, Nakata H, Sekino Y. 1999. High level of adenosine A1 receptor-like immunoreactivity in the CA2/CA3a region of the adult rat hippocampus. Neuroscience 93: 955-967.

Ohno-Shosaku T, Tsubokawa H, Mizushima I, Yoneda N, Zimmer A, Kano M. 2002. Presynaptic cannabinoid sensitivity is a major determinant of depolarization-induced retrograde suppression at hippocampal synapses. J Neurosci 22: 3864-3872.

O'Keefe J, Burgess N. 2005. Dual phase and rate coding in hippocampal place cells: Theoretical significance and relationship to entorhinal grid cells. Hippocampus 15: $853-$ 866.

O'Keefe J, Dostrovsky J. 1971. The hippocampus as a spatial map. Preliminary evidence from unit activity in the freely moving rat. Brain Res 34: 171-175.

Owen SF, Tuncdemir SN, Bader PL, Tirko NN, Fishell G, Tsien RW. 2013. Oxytocin enhances hippocampal spike transmission by modulating fast-spiking interneurons. Nature 500: 458-462.

Pagani JH, Zhao M, Cui Z, Williams Avram SK, Caruana DA, Dudek SM, Young WS. 2014. Role of the vasopressin $1 \mathrm{~b}$ receptor in rodent aggressive behavior and synaptic plasticity in hippocampal area CA2. Mol Psychiatry 20: 490-499.

Pastalkova E, Itskov V, Amarasingham A, Buzsaki G. 2008. Internally generated cell assembly sequences in the rat hippocampus. Science 321: 1322-1327.

Pavlopoulos E, Jones S, Kosmidis S, Close M, Kim C, Kovalerchik O, Small SA, Kandel ER. 2013. Molecular mechanism for age-related memory loss: The histone-binding protein RbAp48. Sci Transl Med 5: 200ral15.

Peterfi Z, Urban GM, Papp OI, Nemeth B, Monyer H, Szabo G, Erdelyi F, Mackie K, Freund TF, Hajos N, et al. 2012. Endocannabinoid-mediated long-term depression of afferent excitatory synapses in hippocampal pyramidal cells and GABAergic interneurons. J Neurosci 32: 14448-14463.

Piskorowski RA, Chevaleyre V. 2012. Synaptic integration by different dendritic compartments of hippocampal CA and CA2 pyramidal neurons. Cell Mol Life Sci 69: 75-88.

Piskorowski RA, Chevaleyre V. 2013. $\delta$-Opioid receptors mediate unique plasticity onto parvalbumin-expressing interneurons in area CA2 of the hippocampus. J Neurosci 33: $14567-14578$.

Ramirez S, Liu X, Lin PA, Suh J, Pignatelli M, Redondo RL, Ryan TJ, Tonegawa S. 2013. Creating a false memory in the hippocampus. Science 341: 387-391.

Remondes M, Schuman EM. 2004. Role for a cortical input to hippocampal area CA1 in the consolidation of a longterm memory. Nature 431: 699-703.

Rogan MT, Staubli UV, LeDoux JE. 1997. Fear conditioning induces associative long-term potentiation in the amygdala. Nature 390: 604-607.

Rogan MT, Leon KS, Perez DL, Kandel ER. 2005. Distinct neural signatures for safety and danger in the amygdala and striatum of the mouse. Neuron 46: 309-320.
Rossato JI, Bevilaqua LR, Izquierdo I, Medina JH, Cammarota M. 2009. Dopamine controls persistence of longterm memory storage. Science 325: 1017-1020.

Rowland DC, Weible AP, Wickersham IR, Wu H, Mayford M, Witter MP, Kentros CG. 2013. Transgenically targeted rabies virus demonstrates a major monosynaptic projection from hippocampal area CA2 to medial entorhinal layer II neurons. J Neurosci 33: 14889-14898.

Royer S, Zemelman BV, Losonczy A, Kim J, Chance F, Magee JC, Buzsaki G. 2012. Control of timing, rate and bursts of hippocampal place cells by dendritic and somatic inhibition. Nat Neurosci 15: 769-775.

Rugg MD, Vilberg KL. 2013. Brain networks underlying episodic memory retrieval. Curr Opin Neurobiol 23: 255-260.

Sahay A, Scobie KN, Hill AS, O'Carroll CM, Kheirbek MA, Burghardt NS, Fenton AA, Dranovsky A, Hen R. 2011. Increasing adult hippocampal neurogenesis is sufficient to improve pattern separation. Nature 472: 466-470.

Saucier D, Cain DP. 1995. Spatial learning without NMDA receptor-dependent long-term potentiation. Nature 378: 186-189.

Schiller J, Major G, Koester HJ, Schiller Y. 2000. NMDA spikes in basal dendrites of cortical pyramidal neurons. Nature 404: 285-289.

Scoville WB, Milner B. 1957. Loss of recent memory after bilateral hippocampal lesions. J Neurol Neurosurg Psychiatry 20: 11-21.

Silva AJ, Paylor R, Wehner JM, Tonegawa S. 1992. Impaired spatial learning in $\alpha$-calcium-calmodulin kinase II mutant mice. Science 257: 206-211.

Simons SB, Escobedo Y, Yasuda R, Dudek SM. 2009. Regional differences in hippocampal calcium handling provide a cellular mechanism for limiting plasticity. Proc Natl Acad Sci 106: $14080-14084$.

Slomianka L, Amrein I, Knuesel I, Sorensen JC, Wolfer DP. 2011. Hippocampal pyramidal cells: The reemergence of cortical lamination. Brain Struct Funct 216: 301-317.

Small SA, Schobel SA, Buxton RB, Witter MP, Barnes CA. 2011. A pathophysiological framework of hippocampal dysfunction in ageing and disease. Nat Rev Neurosci 12: $585-601$.

Solstad T, Moser EI, Einevoll GT. 2006. From grid cells to place cells: A mathematical model. Hippocampus 16: 1026-1031.

Squire LR. 2004. Memory systems of the brain: A brief history and current perspective. Neurobiol Learn Mem 82: 171-177.

Squire LR, Wixted JT. 2011. The cognitive neuroscience of human memory since H.M. Annu Rev Neurosci 34: 259288.

Squire LR, Stark CE, Clark RE. 2004. The medial temporal lobe. Annu Rev Neurosci 27: 279-306.

Suh J, Rivest AJ, Nakashiba T, Tominaga T, Tonegawa S. 2011. Entorhinal cortex layer III input to the hippocampus is crucial for temporal association memory. Science 334: $1415-1420$

Takahashi H, Magee JC. 2009. Pathway interactions and synaptic plasticity in the dendritic tuft regions of CA1 pyramidal neurons. Neuron 62: 102-111.

Thomas MJ, Moody TD, Makhinson M, O'Dell TJ. 1996. Activity-dependent $\beta$-adrenergic modulation of low fre- 
J. Basu and S.A. Siegelbaum

quency stimulation induced LTP in the hippocampal CA1 region. Neuron 17: 475-482.

Tsien JZ, Huerta PT, Tonegawa S. 1996. The essential role of hippocampal CA1 NMDA receptor-dependent synaptic plasticity in spatial memory. Cell 87: 1327-1338.

Tsvetkov E, Carlezon WA, Benes FM, Kandel ER, Bolshakov VY. 2002. Fear conditioning occludes LTP-induced presynaptic enhancement of synaptic transmission in the cortical pathway to the lateral amygdala. Neuron 34: 289-300.

Van Groen T, Wyss JM. 1990. Extrinsic projections from area CA1 of the rat hippocampus: Olfactory, cortical, subcortical, and bilateral hippocampal formation projections. J Comp Neurol 302: 515-528.

Van Strien NM, Cappaert NL, Witter MP. 2009. The anatomy of memory: An interactive overview of the parahippocampal-hippocampal network. Nat Rev Neurosci 10: $272-282$.

Vertes RP. 1992. PHA-L analysis of projections from the supramammillary nucleus in the rat. J Comp Neurol 326: 595-622.

Wang GW, Cai JX. 2006. Disconnection of the hippocampal-prefrontal cortical circuits impairs spatial working memory performance in rats. Behav Brain Res 175: 329336.

Wersinger SR, Ginns EI, O'Carroll AM, Lolait SJ, Young WS III. 2002. Vasopressin V1b receptor knockout reduces aggressive behavior in male mice. Mol Psychiatry 7: 975984.

Wester JC, McBain CJ. 2014. Behavioral state-dependent modulation of distinct interneuron subtypes and consequences for circuit function. Curr Opin Neurobiol 29C: $118-125$.

Whitlock JR, Heynen AJ, Shuler MG, Bear MF. 2006. Learning induces long-term potentiation in the hippocampus. Science 313: 1093-1097.

Wilkerson A, Levin ED. 1999. Ventral hippocampal dopamine D1 and D2 systems and spatial working memory in rats. Neuroscience 89: 743-749.

Wills TJ, Cacucci F, Burgess N, O’Keefe J. 2010. Development of the hippocampal cognitive map in preweanling rats. Science 328: 1573-1576.

Wilson RI, Nicoll RA. 2001. Endogenous cannabinoids mediate retrograde signalling at hippocampal synapses. Nature 410: 588-592.

Witter MP, Amaral DG. 1991. Entorhinal cortex of the monkey: V. Projections to the dentate gyrus, hippocampus, and subicular complex. J Comp Neurol 307: 437-459.

Wouterlood FG, Saldana E, Witter MP. 1990. Projection from the nucleus reuniens thalami to the hippocampal region: Light and electron microscopic tracing study in the rat with the anterograde tracer Phaseolus vulgarisleucoagglutinin. J Comp Neurol 296: 179-203.
Wyss JM, Van Groen T. 1992. Connections between the retrosplenial cortex and the hippocampal formation in the rat: A review. Hippocampus 2: 1-11.

Xie Z, Ma X, Ji W, Zhou G, Lu Y, Xiang Z, Wang YX, Zhang L, Hu Y, Ding YQ, et al. 2010. Zbtb20 is essential for the specification of CA1 field identity in the developing hippocampus. Proc Natl Acad Sci 107: 6510-6515.

Xu W, Sudhof TC. 2013. A neural circuit for memory specificity and generalization. Science 339: 1290-1295.

Xu JY, Zhang J, Chen C. 2012. Long-lasting potentiation of hippocampal synaptic transmission by direct cortical input is mediated via endocannabinoids. J Physiol 590: 2305-2315.

Yamamoto J, Suh J, Takeuchi D, Tonegawa S. 2014. Successful execution of working memory linked to synchronized high-frequency $\gamma$ oscillations. Cell 157: 845-857.

Yeckel MF, Berger TW. 1990. Feedforward excitation of the hippocampus by afferents from the entorhinal cortex: Redefinition of the role of the trisynaptic pathway. Proc Natl Acad Sci 87: 5832-5836.

Young WS, Li J, Wersinger SR, Palkovits M. 2006. The vasopressin $1 \mathrm{~b}$ receptor is prominent in the hippocampal area CA2 where it is unaffected by restraint stress or adrenalectomy. Neuroscience 143: 1031-1039.

Younts TJ, Castillo PE. 2014. Endogenous cannabinoid signaling at inhibitory interneurons. Curr Opin Neurobiol 26: $42-50$.

Younts TJ, Chevaleyre V, Castillo PE. 2013. CA1 pyramidal cell theta-burst firing triggers endocannabinoid-mediated long-term depression at both somatic and dendritic inhibitory synapses. J Neurosci 33: 13743-13757.

Zakharenko SS, Patterson SL, Dragatsis I, Zeitlin SO, Siegelbaum SA, Kandel ER, Morozov A. 2003. Presynaptic BDNF required for a presynaptic but not postsynaptic component of LTP at hippocampal CA1-CA3 synapses. Neuron 39: 975-990.

Zhao M, Choi YS, Obrietan K, Dudek SM. 2007. Synaptic plasticity (and the lack thereof) in hippocampal CA2 neurons. J Neurosci 27: 12025-12032.

Zhu PJ, Lovinger DM. 2007. Persistent synaptic activity produces long-lasting enhancement of endocannabinoid modulation and alters long-term synaptic plasticity. $J$ Neurophysiol 97: 4386-4389.

Ziv Y, Burns LD, Cocker ED, Hamel EO, Ghosh KK, Kitch LJ, El Gamal A, Schnitzer MJ. 2013. Long-term dynamics of CA1 hippocampal place codes. Nat Neurosci 16: $264-$ 266.

Zola-Morgan S, Squire LR, Amaral DG. 1986. Human amnesia and the medial temporal region: Enduring memory impairment following a bilateral lesion limited to field CA1 of the hippocampus. J Neurosci 6: 2950-2967. 


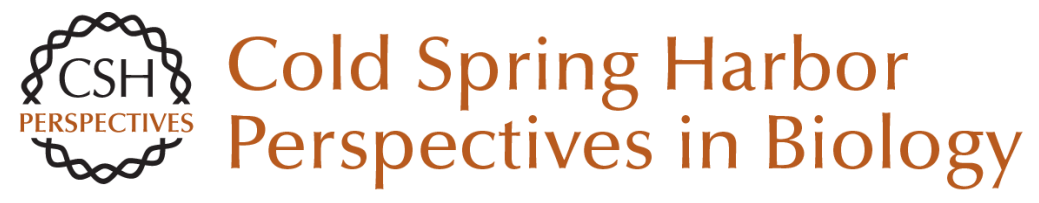

\section{The Corticohippocampal Circuit, Synaptic Plasticity, and Memory}

Jayeeta Basu and Steven A. Siegelbaum

Cold Spring Harb Perspect Biol 2015; doi: 10.1101/cshperspect.a021733

Subject Collection Learning and Memory

Large-Scale Fluorescence Calcium-Imaging Methods for Studies of Long-Term Memory in Behaving Mammals

Pablo Jercog, Thomas Rogerson and Mark J. Schnitzer

Exploring Memory Representations with

Activity-Based Genetics

Mark Mayford and Leon Reijmers

The Origins and Organization of Vertebrate

Pavlovian Conditioning Michael S. Fanselow and Kate M. Wassum

The Corticohippocampal Circuit, Synaptic

Plasticity, and Memory

Jayeeta Basu and Steven A. Siegelbaum

Motor Learning and the Cerebellum Chris I. De Zeeuw and Michiel M. Ten Brinke

The Striatum: Where Skills and Habits Meet Ann M. Graybiel and Scott T. Grafton

Molecular Genetic Strategies in the Study of Corticohippocampal Circuits

Christopher C. Angelakos and Ted Abel

Nonassociative Learning in Invertebrates John H. Byrne and Robert D. Hawkins
The Role of Functional Prion-Like Proteins in the Persistence of Memory

Kausik Si and Eric R. Kandel

Working Memory: Maintenance, Updating, and the Realization of Intentions

Lars Nyberg and Johan Eriksson

Memory Retrieval in Mice and Men

Aya Ben-Yakov, Yadin Dudai and Mark R. Mayford

Reconsolidation and the Dynamic Nature of

Memory

Karim Nader

Memory Consolidation

Larry R. Squire, Lisa Genzel, John T. Wixted, et al.

Structural Components of Synaptic Plasticity and Memory Consolidation

Craig H. Bailey, Eric R. Kandel and Kristen M.

Harris

Associative Learning in Invertebrates

Robert D. Hawkins and John H. Byrne

The Regulation of Transcription in Memory

Consolidation

Cristina M. Alberini and Eric R. Kandel

For additional articles in this collection, see http://cshperspectives.cshlp.org/cgi/collection/

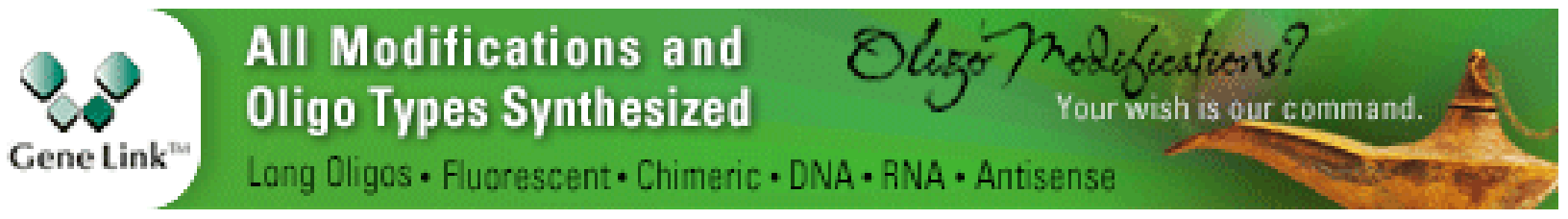

Copyright @ 2015 Cold Spring Harbor Laboratory Press; all rights reserved 